\title{
Research Paper \\ Human Factors Affecting Urban Sprawl in Sanandaj (1976-2015) With Emphasis on Informal Settlements and Peri-Urban Villages
}

\author{
Naseh Abdi ${ }^{1}$, Saeed Zanganeh Shahraki ${ }^{2},{ }^{*}$ Nafiseh Marsousi ${ }^{3}$, Shah Bakhti Rostami ${ }^{4}$
}

1. PhD Student, Department of Geography and Urban Planning, Payame Noor University, Tehran, Iran.

2. Assistant Professor, Department of Geography and Urban Planning, Faculty of Geography, University of Tehran, Tehran, Iran.

3. Associate Professor, Department of Geography and Urban Planning, Payame Noor University, Tehran, Iran.

4. Assistant Professor, Department of Geography and Urban Planning, Payame Noor University, Tehran, Iran.

citation: Abdi, N., Zanganeh Shahraki, S., \& Marsousi N. (2016). Human Factors Affecting Urban Sprawl in Sanandaj (1976-2015) With Emphasis on Informal Settlements and Peri-Urban Villages. Journal of Rural Research. 7(3), 564-581. http://dx.doi.org/10.21859/jjr-070310

: http://dx.doi.org/10.21859/jjr-070310

Received: 4 Apr. 2016

Accepted: 21 Aug 2016

Keywords:

Urban sprawl, In-

formal settlements,

Peri-urban villages,

Migration, Sanandaj

\begin{abstract}
A B STRACT
An increase in urban sprawl and the physical area has occurred increasingly in most of the cities of the Iran in the previous decade. Urban sprawl or the fast physical development and growth in adjoining areas of the main city is a phenomenon experienced by most cities in Iran. Varied reasons are accountable for it. In this study, the most important factors influencing the horizontal development of Sanandaj, particularly the role of informal neighborhood and nearby villages, have been investigated. The current study examines the role of social revolution including land informs and urban management in increasing migration and physical development of city- through the emergence of free neighborhoods and the joining of nearby cities to Sanandaj. The method of the study was descriptive-analytic. The pictures captured by TM, OLI and Landsat 588 satellites, which were analyzed by ArcGIS. The results demonstrate that a large number of settled people caused the emergence of 13 open neighborhoods in an area of 536 hectares particularly from 1976-1986 which led to the joining often nearby villages to the city, consequently bringing about urban sprawl of Sanandaj in the recent four decades. Moreover, there are many communities around the city which have the potential to join with the city leading to the incoherence and disconnected in the context of city.
\end{abstract}

\section{Extended Abstract}

\section{Introduction}

$\mathbf{U}$ rban sprawl and scattered development of cities is now one of the most controversial issues in developing as well as in developed countries. The term "Urban sprawl" which was proposed early for suburbanization growth of developed countries, has several meanings, including horizontal expansion, urban distribution, uncontrolled growth, leapfrog development, low density expansion and so forth. (Zanganeh Shahraki, Majidi Heravi, \& Kaviani, 2012). Recently, in Iran also this phenomenon has occurred due to varied reasons in different large and small cities.

Researchers and scholars have studied the contributors of urban sprawl. They reached to different factors like rural - urban immigration, suburbanization, inability of ad- 
ministrative organizations in controlling development in urban boundaries, population growth, life style, topographic situation, construction of highways, land market, master and comprehensive plans of cities and etc (Zanganeh Shahraki, et al., 2012) All these studies included different cities in different geographical locations.

In the present investigation, the city of Sanandaj situated in west of Iran is selected as the case study. This city has experienced a high amount of urban sprawl and expansion in four last decades. It is one of the most fast growing cities despite its topographical situation which is dominated by mountains all around. The aims of this study are two tires. First, to analyze the amount and direction of sprawl with satellite images and second to examine the factors and primary contributors of Sanandaj's sprawl emphasizing on informal settlements and peri - urban villages.

\section{Methodology}

Five satellite images of the Sanandaj from Sensor TM and OLI Satellite Landsat 5 \& 8 relating to the years 1977 , 1986, 1998, 2005, and 2015 were used to check the urban growth and draw the maps. Sanadaj topographic map with the scale of 1:25,000 was used and the RMSE error was calculated to be less than 0.5 pixels. The nature and reasons of urban sprawl were determined using several methods like demographic analysis, studying the villages around the city, review the history of informal settlements to see how they could undergo the expansion.

\section{Result}

First the urban growth in Sanandaj has been explained from the results of satellite images. The maps derived from images show thatthe city of Sanandaj, the capital city of Kurdistan province, has experienced a very high growth rate in urban development and expansion since 1977. The area of the city was 397 ha in the first period (1977), but quadrupled i.e. became 1703 ha in the next period (1986), about 3500 ha in 1998, 3815 ha in 2005 and finally became 4066 ha in 2015. As evident, the urban sprawl has a specific characteristic in Sanandaj in last four decades; the area of the city has increased about ten times more, whereas the population has increased just 6 times. The population density has decreased from 241 to 95 people per hectare. In addition to high expansion growth rate, the scattered development, and non-attached fabric especially because of the topographic structure is another typical characteristic of this capital city.

\section{Discussion}

Initially, there have been a large number of villages around this city but with the increment in urban built-up area, some of them have annexed to the city and now they are a community of the main city. There are about 194 villages in the county of Sanandaj which can be divide into three groups: first, villages that have already merged to the main city, second, villages that are annexed but not accepted by the administration or will be annexing in the near future, and third,. the villages which are likely to be annexed if the urban sprawl is not controlled. Villages like Jourabad, Mobarakbad, Farjeh, Khanghah and others belong to the first group while as many as six villages are in the thirdgroup.

Another reason of urban sprawl in Sanandaj is high rate of migration which settled in the suburbs of the city and formed informal settlements. Few examples of such settlements are Abbas abad, Shohada, Golshan, Kamiz, and Ghafour. They are now a part of the city. Analysis revealed that about 536 ha of the city are informal settlements which is inhabitated by $2,21,468$ people.

\section{Conclusion}

All types of Iranian cities, big, medium and small, have expanded rapidly in last 4-5 decades. Snanadaj is one the medium sized cities which has grown physically and spatially very fast and its area has reached more than 4000 ha from just 397 ha in about 4 decades. Each city has its specific reasons and causes for the urban sprawl. In the case of Sanandaj, the major human factors affecting urban sprawl areare informal settlements and peri-urban villages. Therefore, to control urban sprawl of this city and also to direct and strengthen the existing neighbors, these two causes must be analyzed. 


\title{
تأثير مؤلفههاى انسانى بر يراكنش افقى شهر سنندج با تأكيد بر اسكان غيررسمى و روستاهاى يبراشهرى
}

\author{
ناصح عبدى'، سعيد زنكنه شهركى" "نفيسه مرصوصى"، شاهبختى رستمى" \\ ا - دانشجوى دكترى، كروه جغرافيا و برنامهريزى شهرى، دانشكاه ييام نور، تهران، ايران.

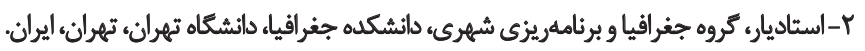

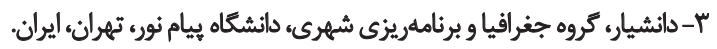

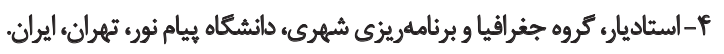

\begin{abstract}
حكيد

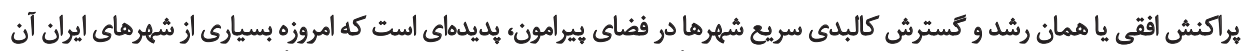

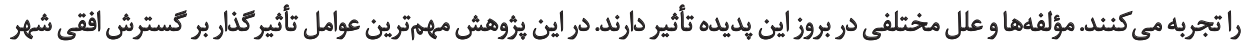

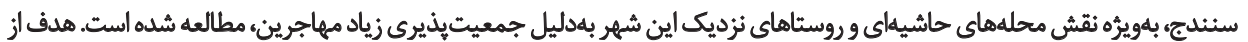

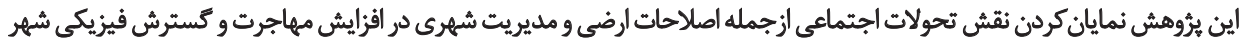

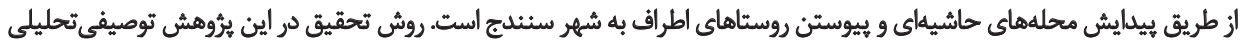

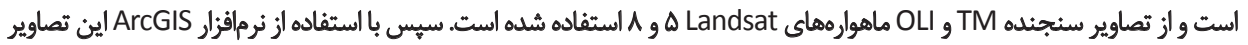

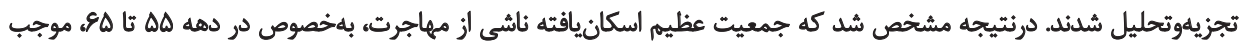

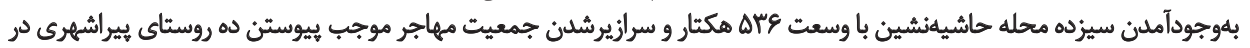

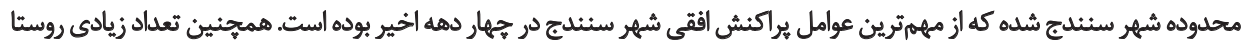

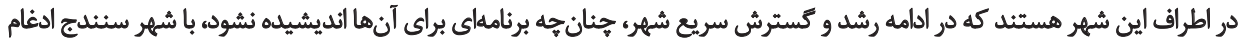

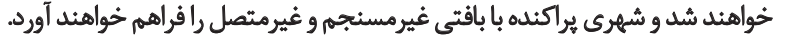

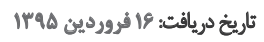

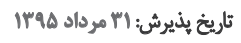

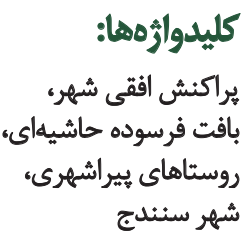

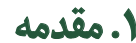

يراكنش شهرى، رشد بي رويه و... ترجمه شده است Zanganeh)

.Shahraki, et al., 2012)

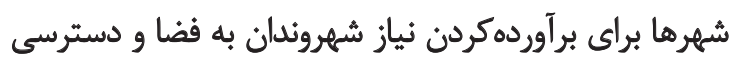

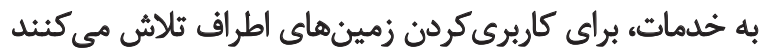

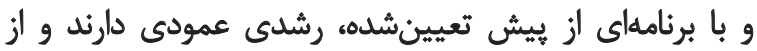

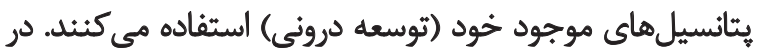

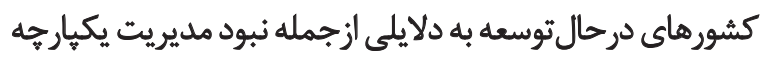

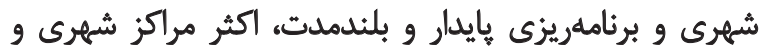

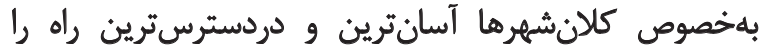

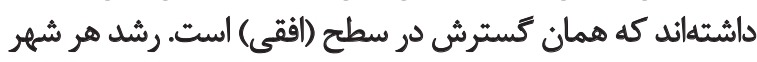
تابعى از عوامل مختلف است.

كرجه يك يا جندعامل بهتنهايي در كسترش افقى شهرها

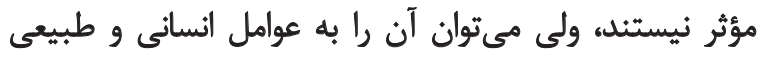

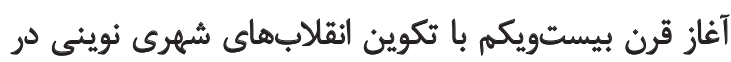

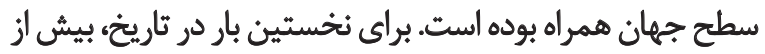

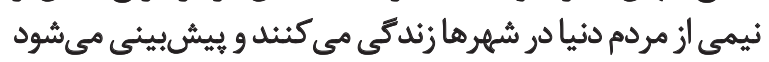

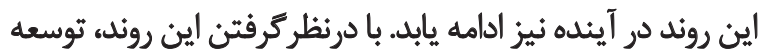

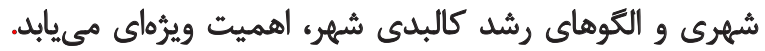

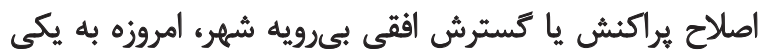

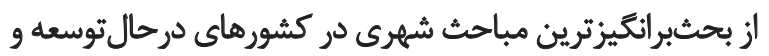
توسعهيافته تبديل شده است. باتوجهبه اينكه اكثر شهرهاي ايران در جئد دها اخدير

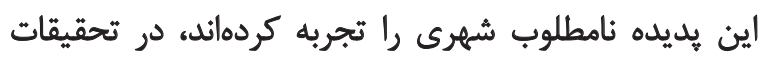

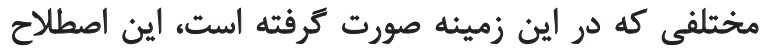

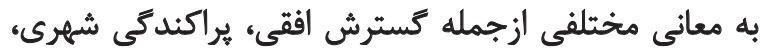




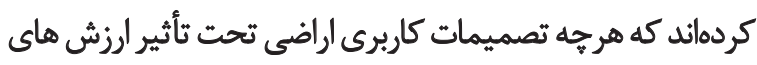

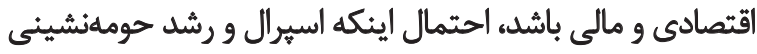
اتفاق بيفتده بيشتر است (Ladd, 1998; Lewis, 2001). در تلاش براى بررسى علل بيدايش بديده كسترش افقى شهر،

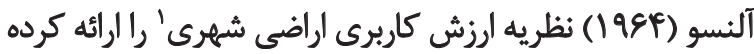

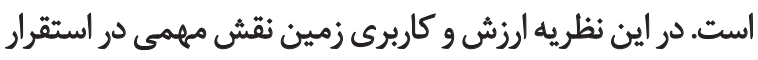

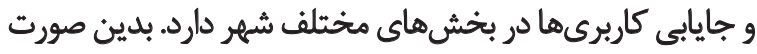

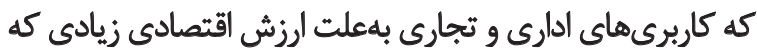

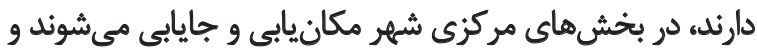

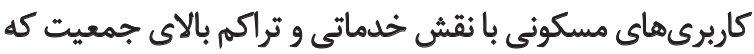

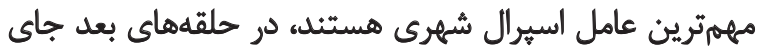

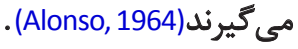

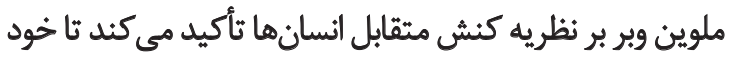

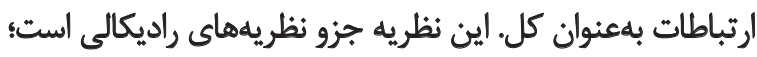

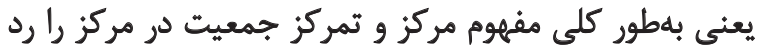

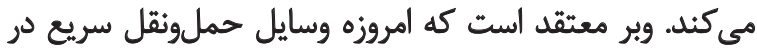

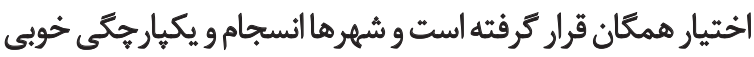

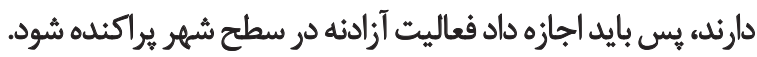

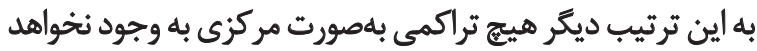

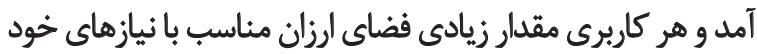
بهدست مي آررد (Papoli Yazdi \& Rajabi Sanjerdi, 2013).

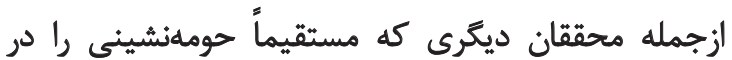

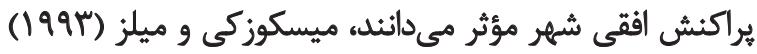

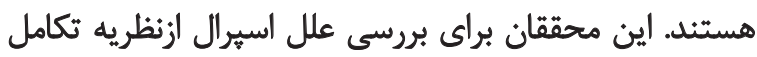

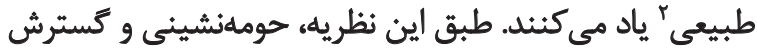

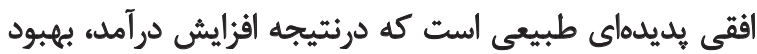

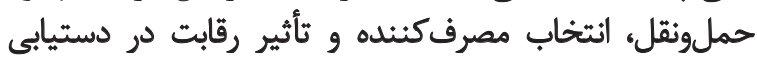

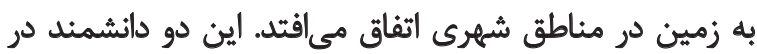

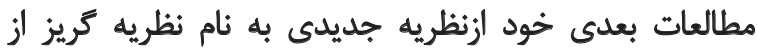

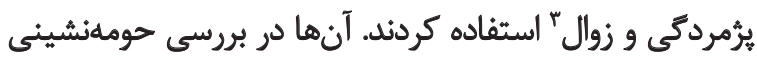

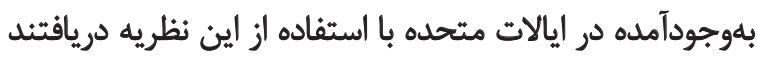

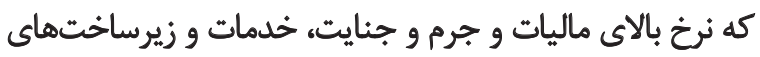

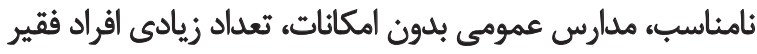

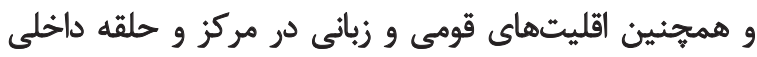

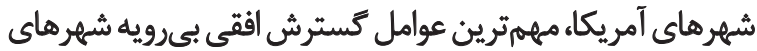
اين كشور بوده است (Mieszkowski, \& Mills, 1993).

ازجمله محققانى كه در رابطه با كسترش فضايى شهرهاي

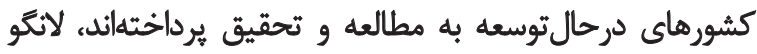

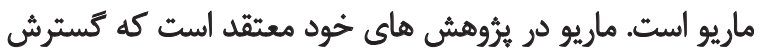

1. Land value

2. Natural evolution

3. Flight from Blight
تقسيمبندى كرد. عوامل طبيعى در اكثر شهرها ثابت و تابع

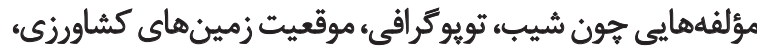

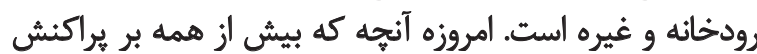

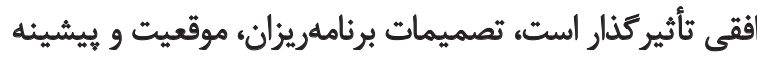

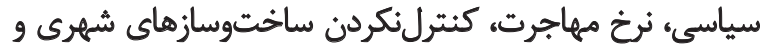

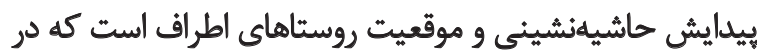

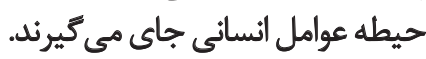

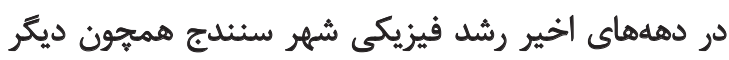

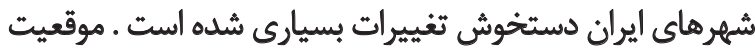

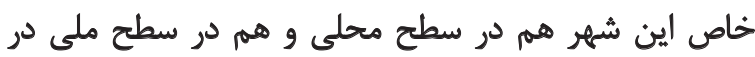

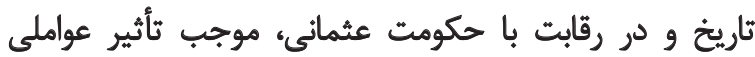

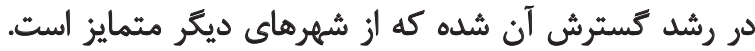

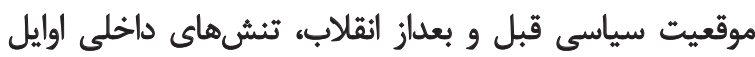

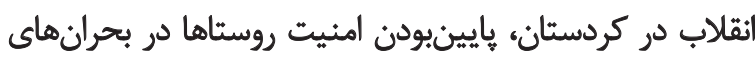

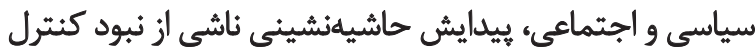

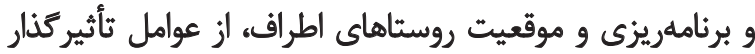

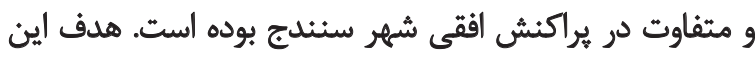

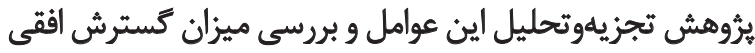
شهر سنندج در جهار دها اخير است.

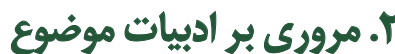

توسعه مطلوب شهرى عبارت است از كسترش هماهنى و و

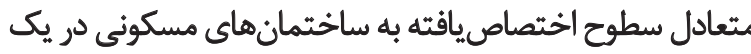

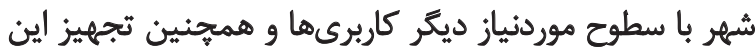

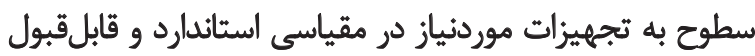

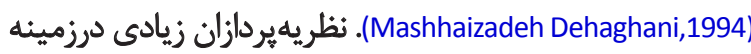

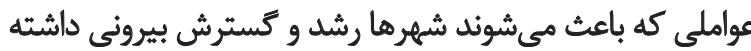

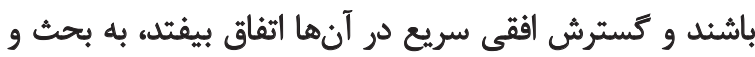

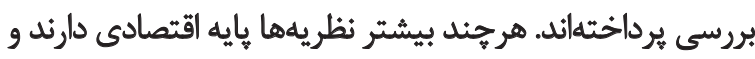

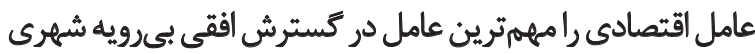

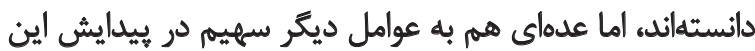

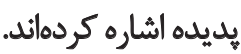

بروكنر و فانزلر (194r) در جستوجوى علتهاي اسيرال

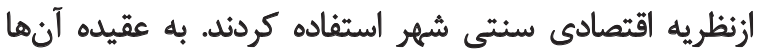

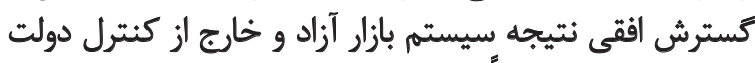

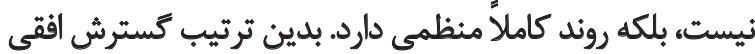

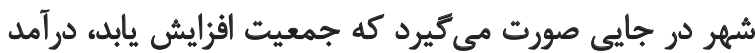

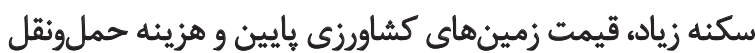

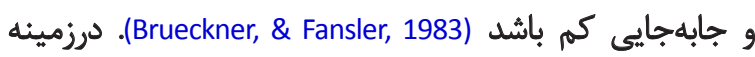

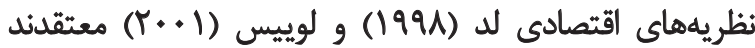

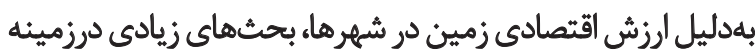

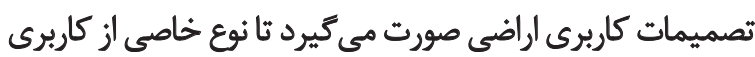
براي قطعهاى از زمين درنظر كرفته شود. هميجنين آنها آنها اشاره 


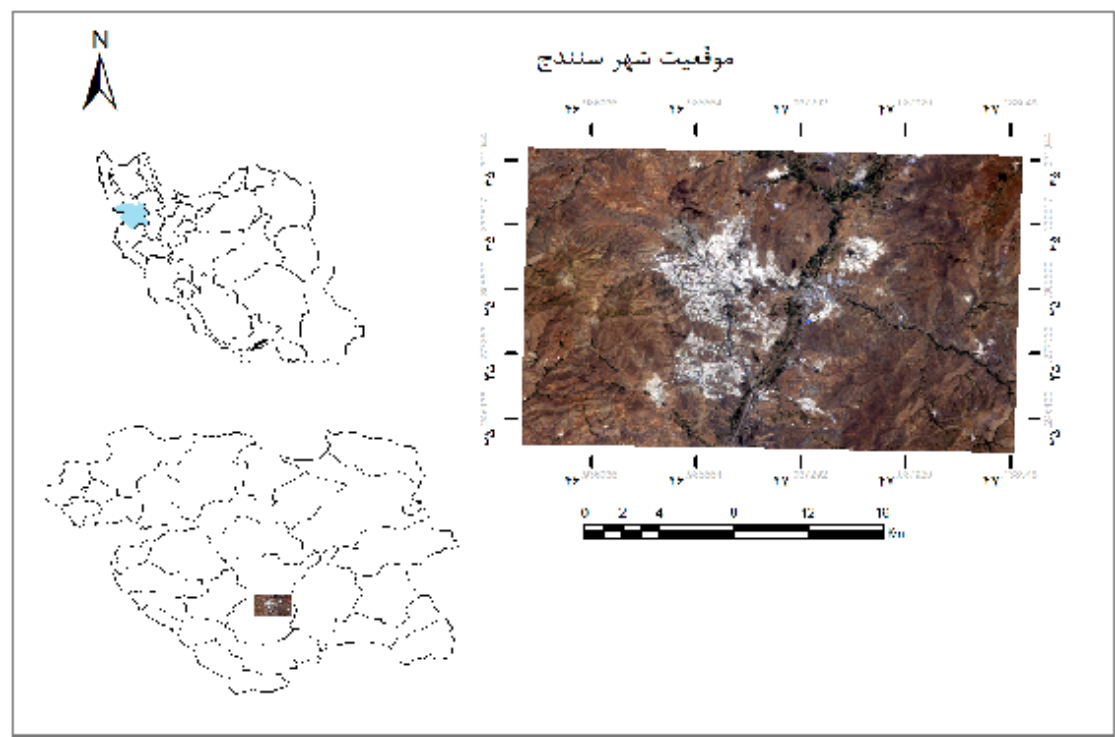

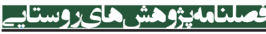

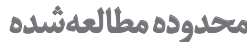

شهير سنتدج در شمال غربى ايران واقع شده و مركز استان

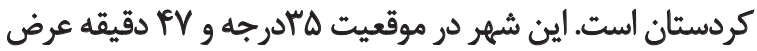

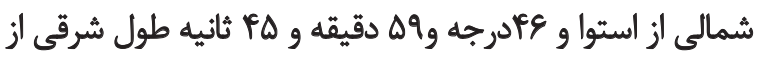

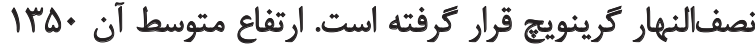
متر از سطح درياست - Statistics Center of Sanandaj Municipal فيهر سنتدج ازنظر طبيعى بين تيههايى در يك جام

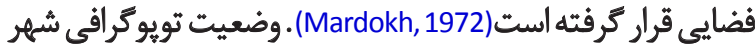

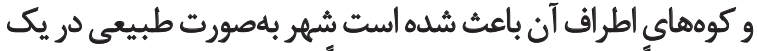

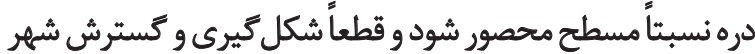

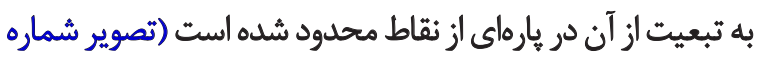

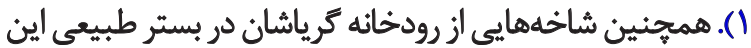

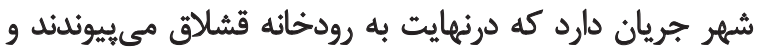

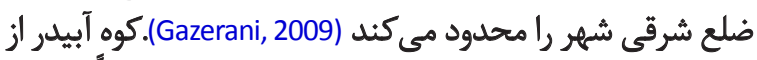

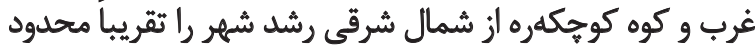

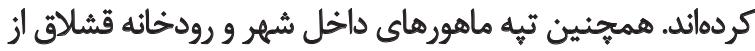
جنوب شرقى رشد و كسترش شهر راجهت دادئ دادهاند.

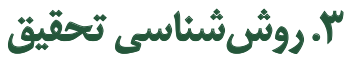

در اين تحقيق براى ترسيم نقشه مراحل رشد وكسترش درش

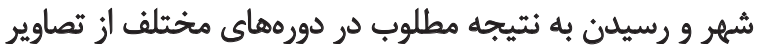

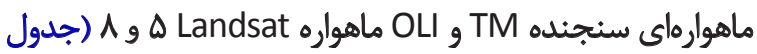

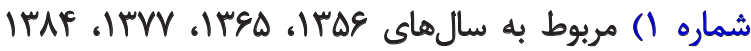

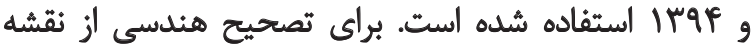

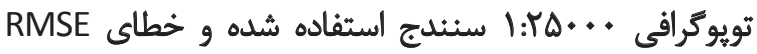

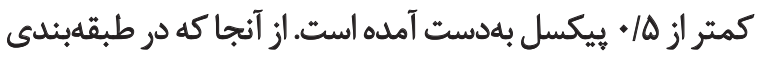

فضايى ناموزون شهرى از ويزّكى هاى شناختهشده بيشتر شهرهاى

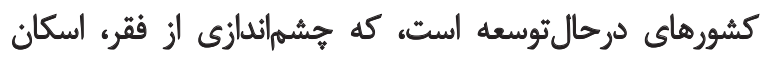

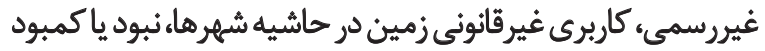

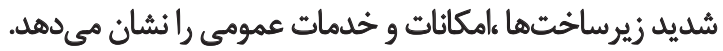
در اين كشورها فرايند شهرنشينى با تأخير صورت كرفته و در

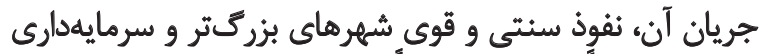

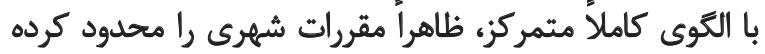

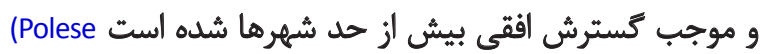

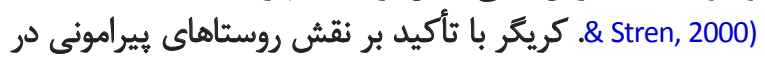

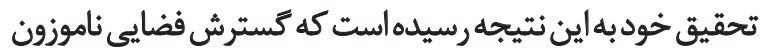

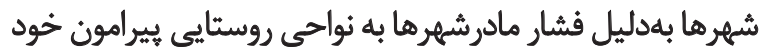

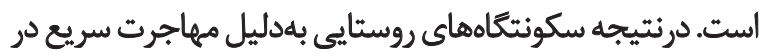

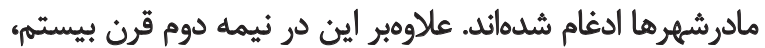

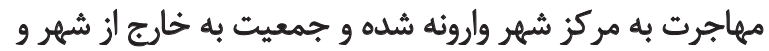

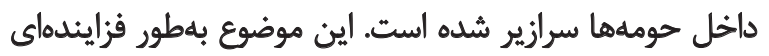

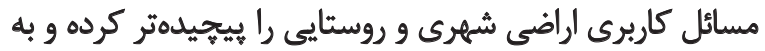

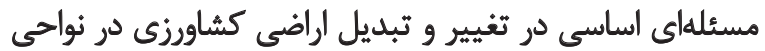
بيرامون مادرشهرها درآمده است. تفاوت در ديدكاههاي علل يراكنش افقى بيشتر بهدليل تفاوت

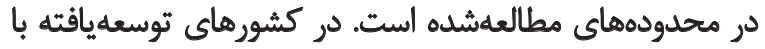

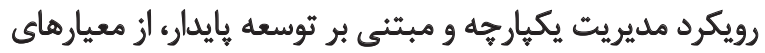

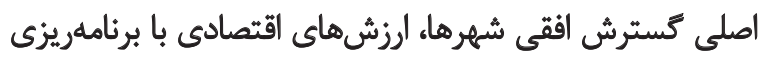

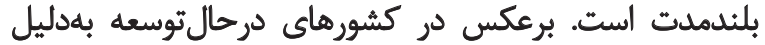

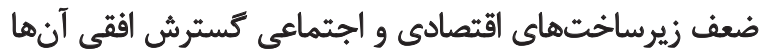

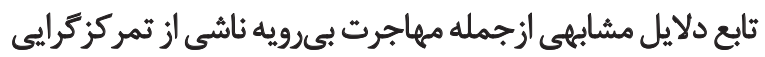

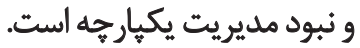




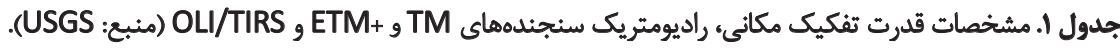

\begin{tabular}{|c|c|c|c|c|c|}
\hline تاريخ كريتن & تفين كروماتيك بائد & 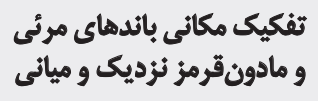 & باندهاي حرارتى مكانى & راديومتريكى & ماهواره/سنجنده \\
\hline June 11, 1977 & 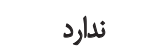 & $r q=v q$ & $M F+R F^{\prime}$ & عبيت & لثدست MSS/T \\
\hline $\begin{array}{c}\text { June } 7,1986 \\
\text { June } 8,1998 \\
\text { May } 30,2006\end{array}$ & ندارد & . & 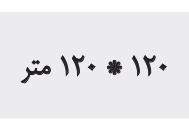 & Aيت & لندست TM/ه \\
\hline June 3, 2015 & 10 & 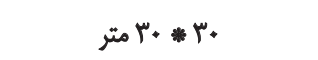 & 1... 1. متر & عاليث & للندست OLI/TIRS/A \\
\hline
\end{tabular}

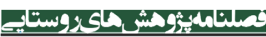

زمينهاى زيرساخت و كاهش تراكم جمعيتى (بهجز در مواردى

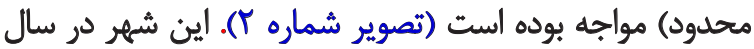

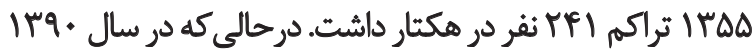

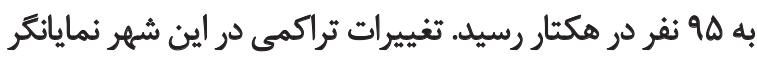

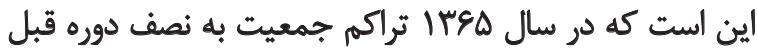

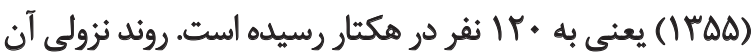

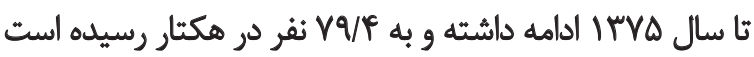

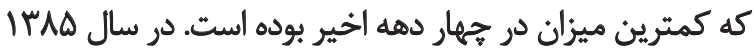

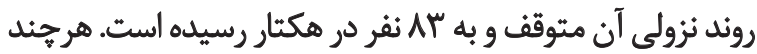

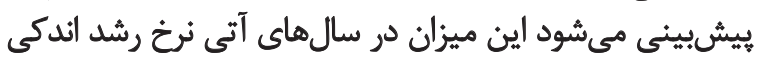

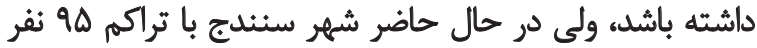

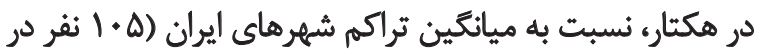
هكثار) بايينتر است (جدول شماره ب).

با بررسى عكسىهاى ماهوارهاي و تبديل آنها به نقشه، ميزان

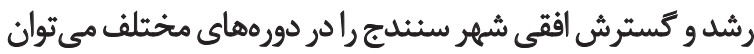

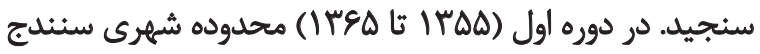

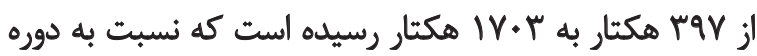

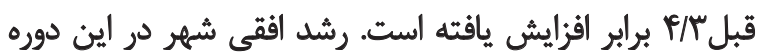

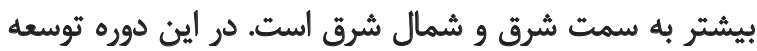

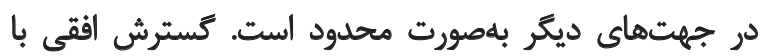

تصاوير از الكَوريتم حداكثر احتمال استفاده شده و كلاسهاى

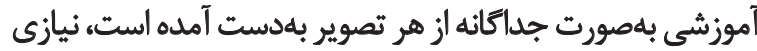

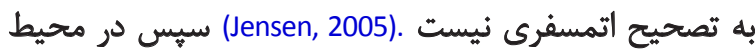

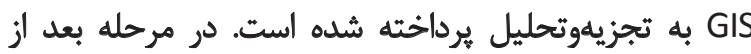

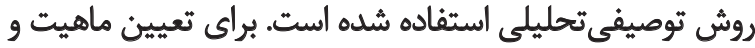

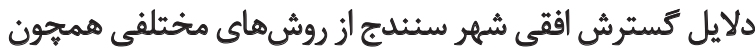

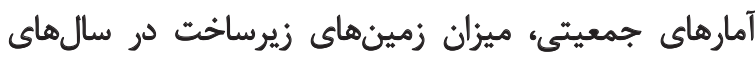

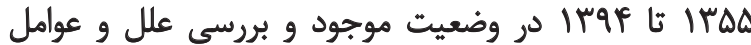
مختلف انسانى استفاده شده است.

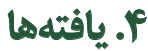

$$
\text { كسترش اققى شهر سندج }
$$

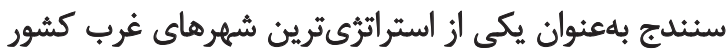

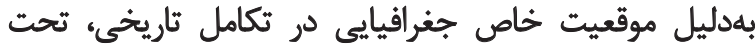

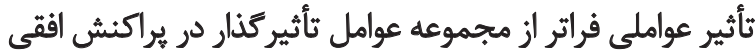

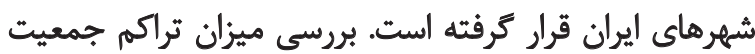

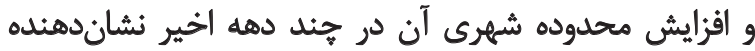
تحولات بسيار سريع در اين شهر است. شهر سنندج در جهل سال اخير همواره با روند افزايش

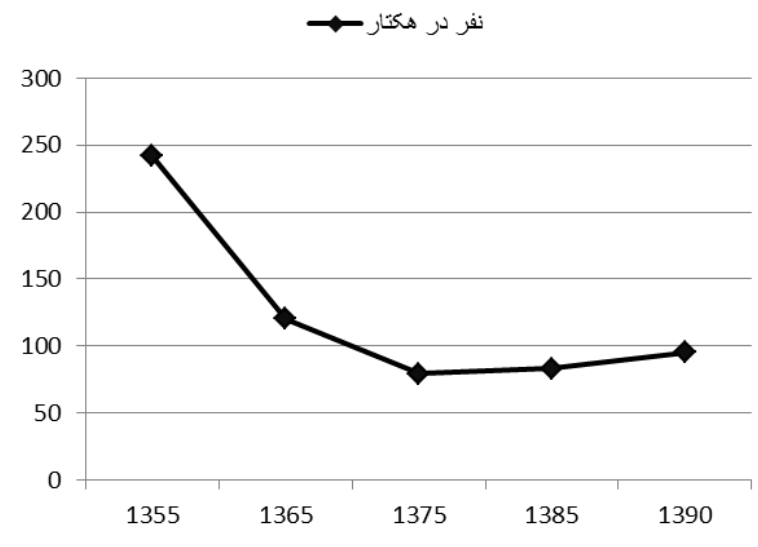




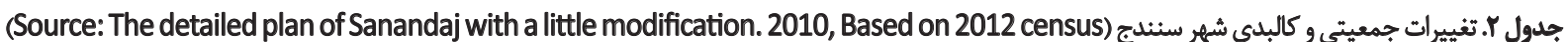

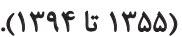

\begin{tabular}{|c|c|c|c|c|c|}
\hline Irqq & IrNA & IIVQ & $\mid r F A$ & IT৯A & 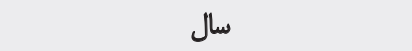 \\
\hline "WrVATA. & MIEATY & mWA.A & r.forr & qQAnT & جمعيت \\
\hline $1 \Delta / \Delta \%$ & $1 r \%$ & $r e / r \%$ & $11 \% \%$ & $V \Delta \%$ & افزايش جمعيت نسبت به دوره قبل (درصد) \\
\hline$* 9 \Delta$ & Ar & va/e & ir. & ris & تراكم جمعيث \\
\hline$f+48$ & rAlQ & ra.. & $I V \cdot r$ & mqv & مساحت (هكتار) \\
\hline | & 9-1/برابر & ك ابرابر & T بر برابر & - & تغيير هساحت نسبت به دوره قبل \\
\hline
\end{tabular}

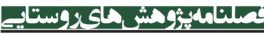

مقطع زمانى توسعه فيزيكى شهر بهصورت بييوسته و متصل بُعد

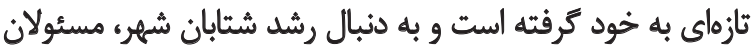

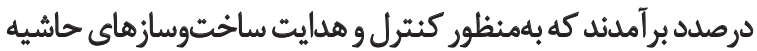
شهر، بسترهاي مناسبى در قالب طرحهاي آمادهسازى فراهم كئند

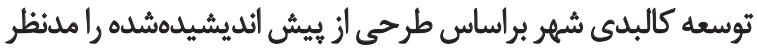

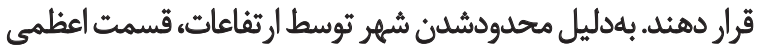

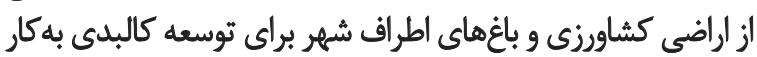

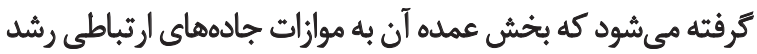

سرعت زياد در زمينهاى با شيب زياد و ناهموار و اغلب با كاربرى

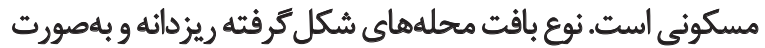

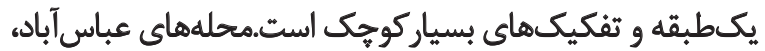

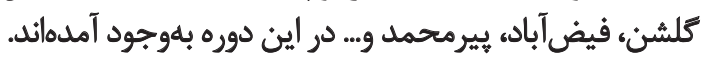

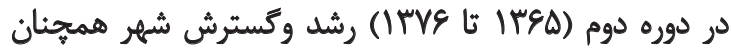

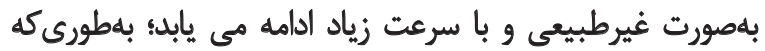

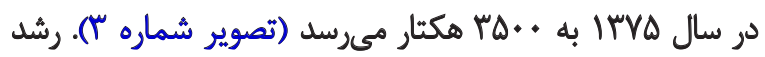

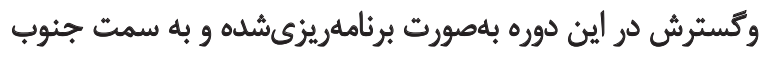

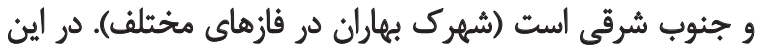
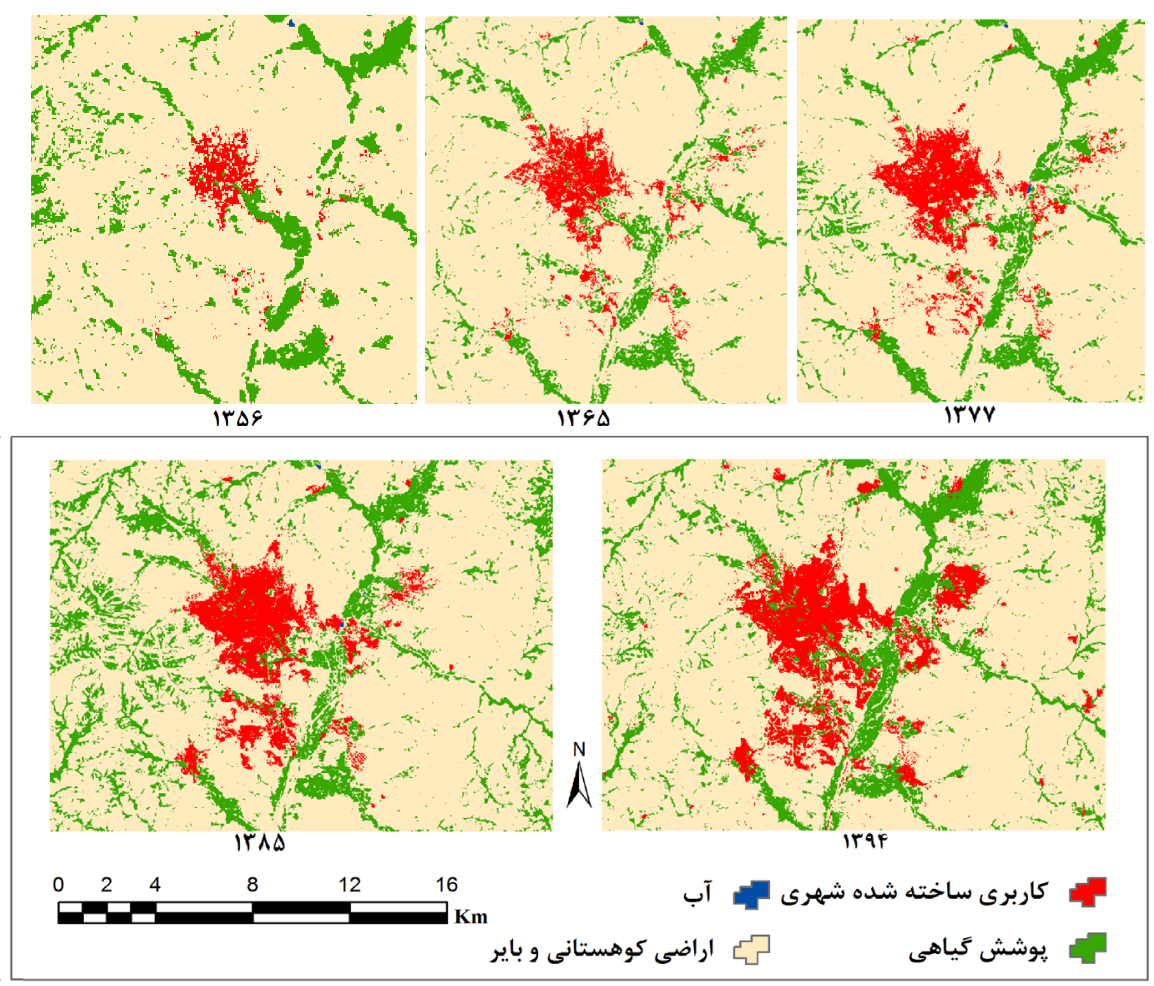


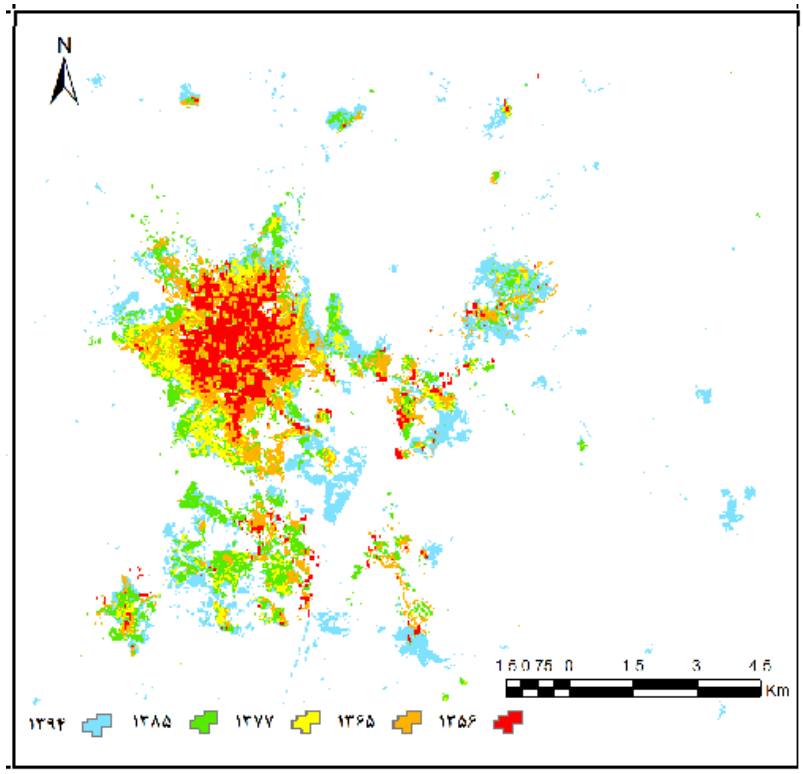

در سال بوq ا محدوده شهرى سنئدج به أهزار و 98 هكتار

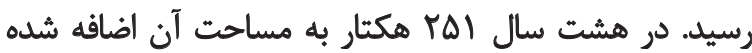

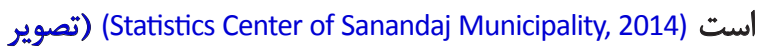

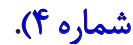

عوامل مؤثر بر كسترش الفقى شهر سندج

$$
\text { مهاجرت و اسكان غيررسمي }
$$

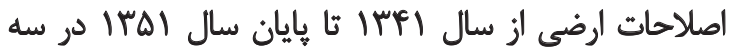

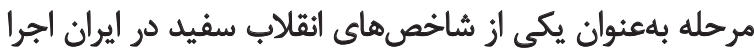

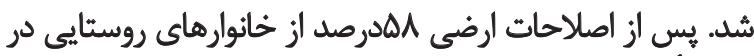
زمره خُر دمالكان صاحب زمين قرار داشتئد (Mahdavi, 2001).

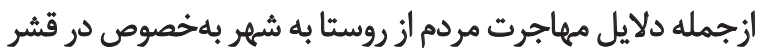

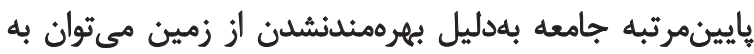

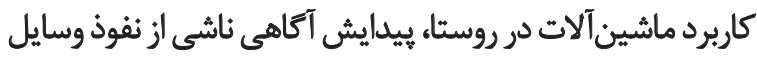

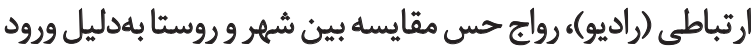

كُيترش شتابان كالبدى شهر سنيندج در دوره

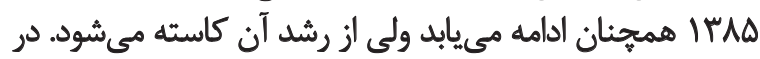

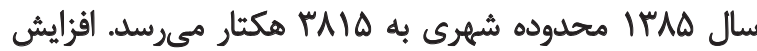

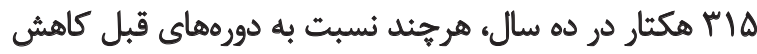

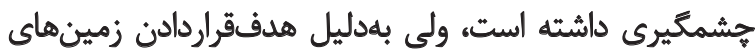

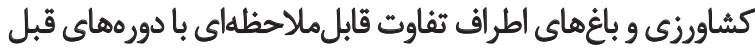

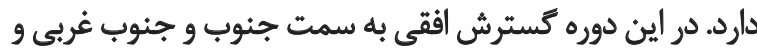

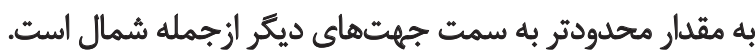

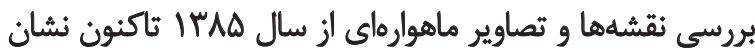

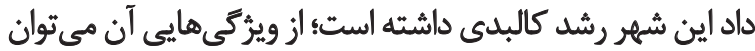

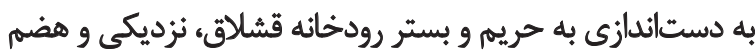

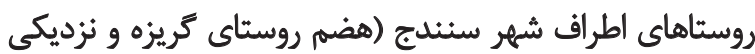

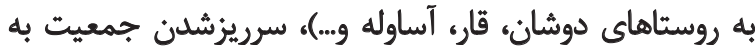

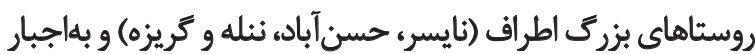

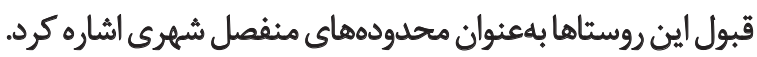

جدول r. نسبت مهاجرت به رشد جمعيت شهرى سنثلج.

\begin{tabular}{|c|c|c|c|c|}
\hline نرخ جمعيت & درحد مهاجران به كل رشيد جمعيث دوره & تعداد مهاجران واروشيده در دوره سرشمارى & تعداد جمعيت & שال \\
\hline$V / A$ & $\Delta Q / \Delta$ & eraw & r.PATr & \\
\hline$r / 8$ & $\Delta \cdot / 1$ & mrar & $M W A+\Lambda$ & Irva \\
\hline$t / e$ & $R T / N$ & 189.8 & MIEATT & IrAD \\
\hline$\mu / r$ & Fq/f & reqeq & rvara. & $1 \% q$. \\
\hline
\end{tabular}




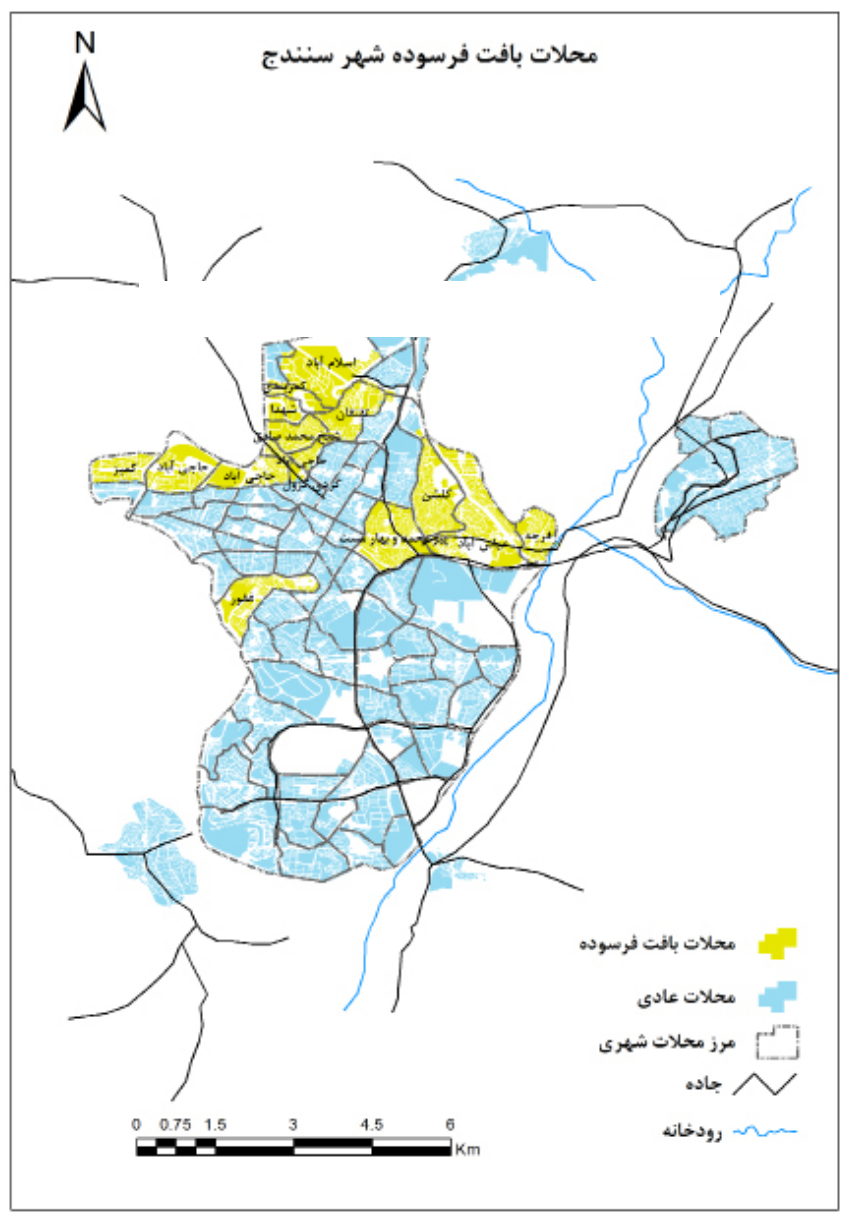

حركات ضدانقلابى بلويزه در شهر سنتدج، تمركز تلاشهاى

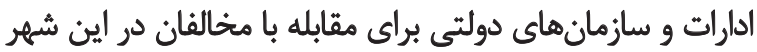

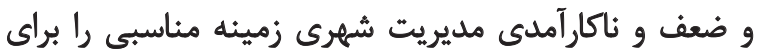

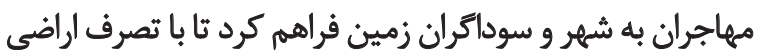

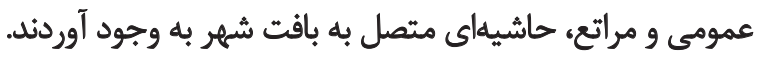

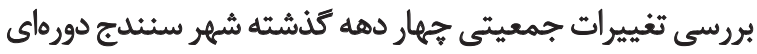

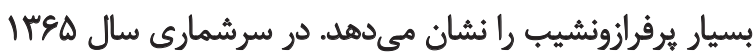

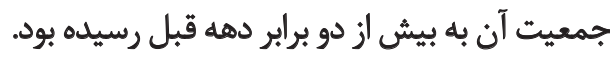

در ده سال نرخ رشد طبيعى جمعيت اين شهر به بيشترين

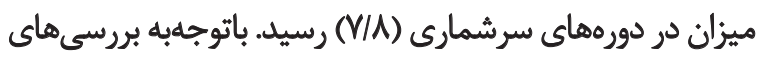

سازوكارهاى آموزشى (سياه دانش) و يبدايش وابستگى به اقتصاد

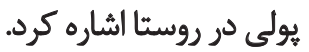

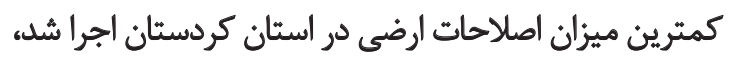

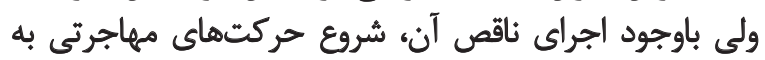

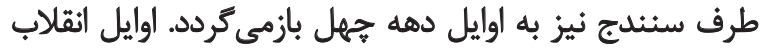

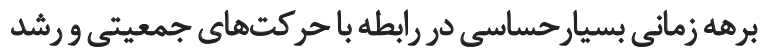
فيزيكى شهر سنثدج است. دهه

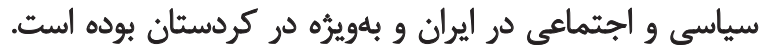

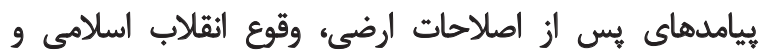

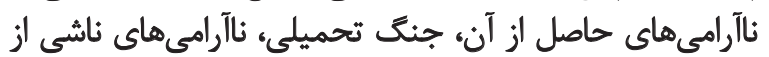

جدول F. تغييرات مساحت مناطق حاشيهنشين شهر سيندج (بدون احتساب مناطق مثفصل شهرى).

\begin{tabular}{|c|c|c|c|c|}
\hline IrAD & Irvo & Ires & ITDQ & \\
\hline$\Delta r g / r$ & $\Delta r \& / T$ & $\Delta F+/ T \Delta$ & $11 \% / \Delta$ & مساحت حاشيه (هكتار) \\
\hline
\end{tabular}




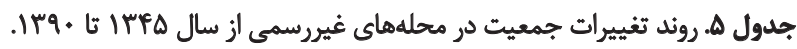

\begin{tabular}{|c|c|c|c|c|c|c|}
\hline سال مجله & سال تأسيس & ITDS & IMED & ITVA & irno & 149. \\
\hline حاجى آباد & IMPo & IVe. & 9APQ & Irate & ive.r & $r \cdot A \cdot Y$ \\
\hline جمه حاجى نسه & Imes & $1 f+$. & Ifq. & $r+1+$ & $r v \cdot 1$ & riqr \\
\hline شيخ محملصادق & inf. & $M \Delta$ & $\Delta V$. & $\lambda+r+$ & IITEF & IMTIF \\
\hline كردى كرول & $|r \Delta|$ & - & $r \cdot Y \cdot$ & MIV & MEAP & PFIQ \\
\hline تقثمقان & ITAA & - & pq.. & DqW & Wes & 9119 \\
\hline أسلام/آباد & ire. & - & r. r. & rAP. & rer & PEAF \\
\hline كمرينلى & Irey & - & ETVD & Ar.. & 1.981 & Irave \\
\hline غَفور & imes & - & $\Delta \& A Y$ & mir & $1+p \mid$ & Imve \\
\hline ييرمحمد و بهارمس & ire. & irat. & $181 \ldots$ & $r \cdot r^{-}$ & reftr & MIMPF \\
\hline عباس آلباد & Iroq & - & r. rq & FIrAq & $\Delta F \cdot A r$ & ETMM \\
\hline فرجه & Irer & - & Pa.. & onft & VIrI & NE\&D \\
\hline كلشن & Iro. & $\Delta q$. & $V \cdot r_{1}$ & $\Delta r \cdot \Delta$ & Qurr & 1181. \\
\hline شهيا & Irer & eare & $18 \mathrm{VV}$ & riqg. & TIFAA & melf \\
\hline جم: & & YOAIV & $1110 \mathrm{~V}$. & |FEAF| & 19VATY & MIIFA \\
\hline
\end{tabular}

منبع: استخراج نُارئده براساس سرشمارىهاى عمومى نثوس و مسكن.

شوراى انقلاب بهمنظور حل مسئله مالكيت اراضى شهرى، قانون

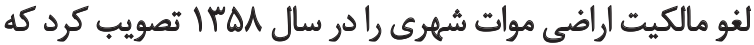

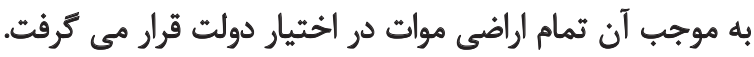

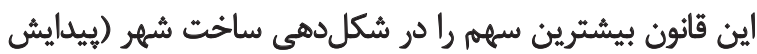
بافت حاشيهاى) بعداز انقلاب تاكنون داشته است (Kamrava, 2009).

ظرف مدت يك سال از اجراى قانون لغو مالكيت اراضى موات

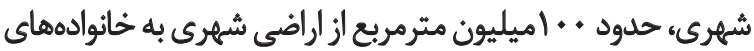

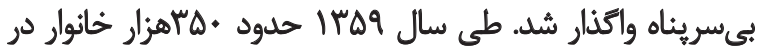
كل كشور براى مسكن زمين دريافت كردند - The national orga

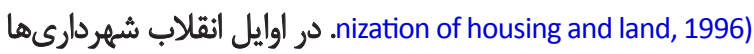

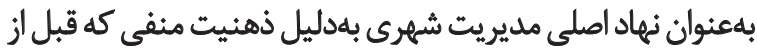

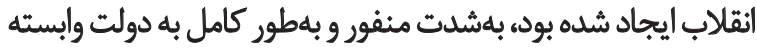

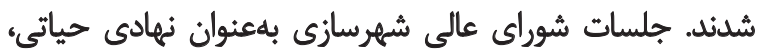

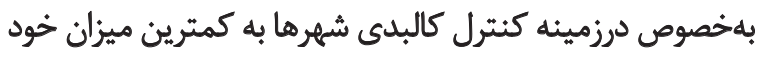

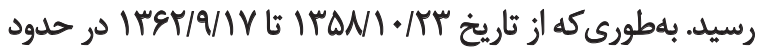

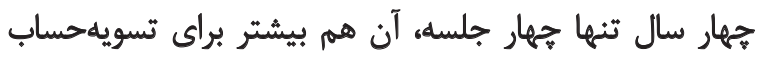

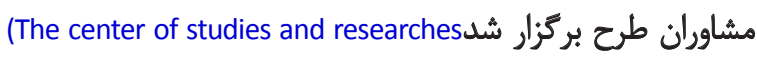
.of urban development, 1991)

استقرار طبقات مختلف اجتماعى در محله هاى شهر سنيدج در

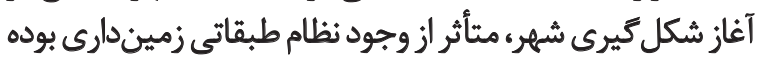

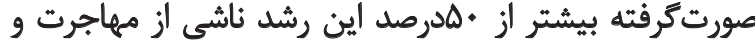

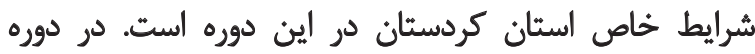

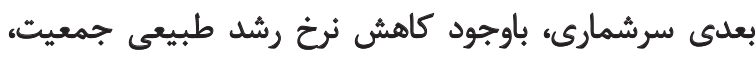

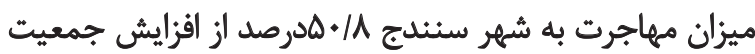

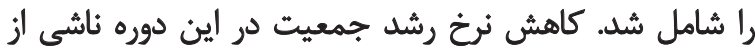

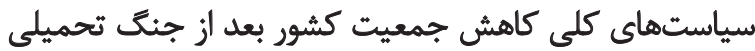

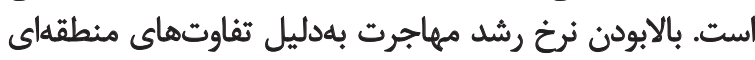

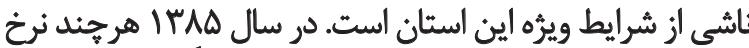

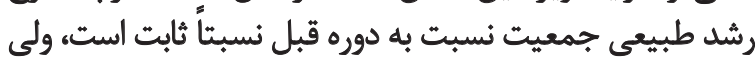

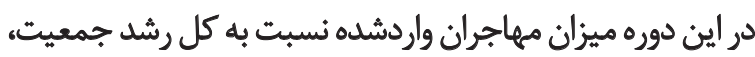

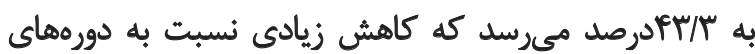

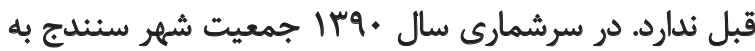
طبه

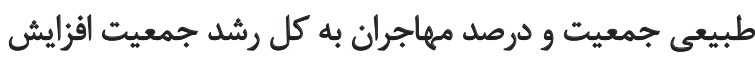
يبدا مى كند (جدول شماره سم). در دوران نبود مديريت شهرى (اوايل انقلاب) در كل كشور

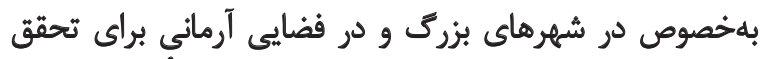

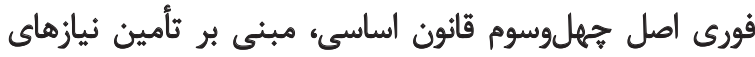

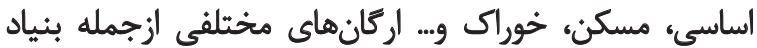

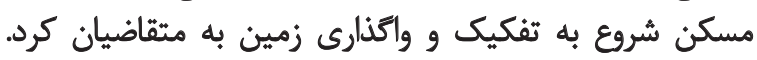




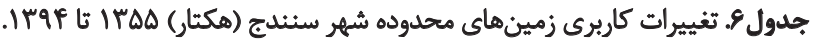

\begin{tabular}{|c|c|c|c|c|c|}
\hline iraf & IrAD & irry & ires & iros & \\
\hline$r \cdot V N A$ & mIr/A & $1019 / 4$ & $\| F V / \Delta$ & - & كاربرى ساختهشله در هر دوره \\
\hline$A V / N$ & $\Delta e / r$ & $m / m$ & $\Delta V / N^{\infty}$ & - & مقدار اراضى كشاورزى تغييريافته به كاربرى ساختهلشهه \\
\hline
\end{tabular}

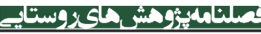

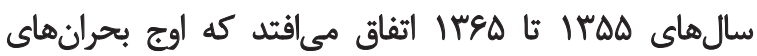
سياسي و اجتماعي ايران بلويرُه در كردسيتان است. فيت.

بنابراين در شهر سنئدج رويدادهاي سياسي واجتماعي بهعنوان

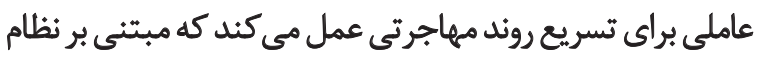

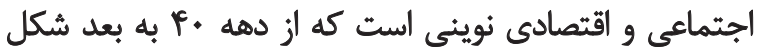

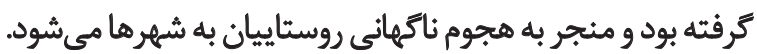

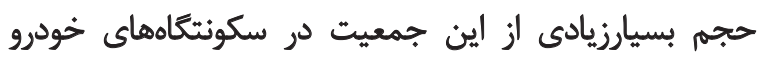

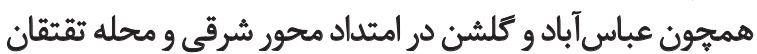

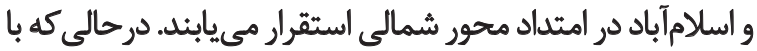

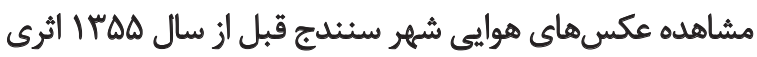
از اين محلههاي ديده نمى مشود.

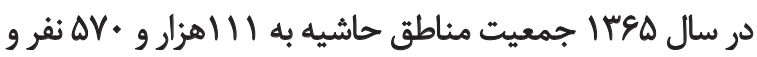

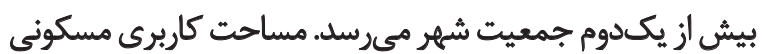

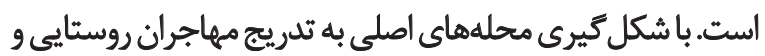

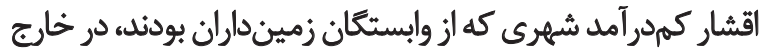

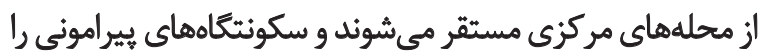

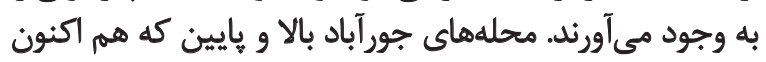
جزئى از بافت قديم شهر محسوب مي شيوند، در راستاى جنين

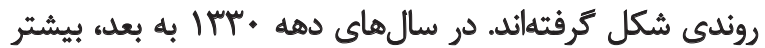

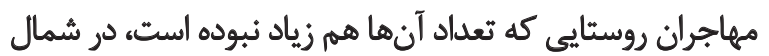

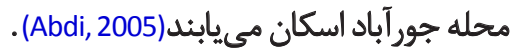

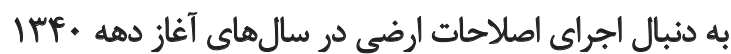

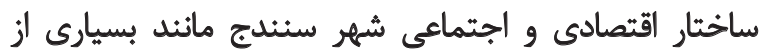

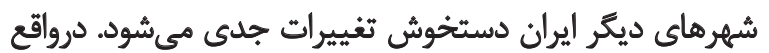

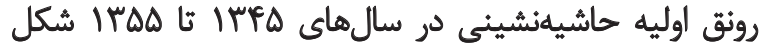

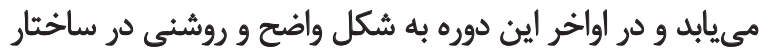

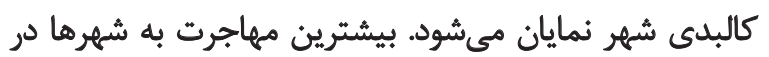

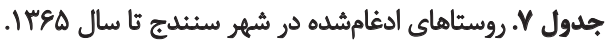

\begin{tabular}{|c|c|c|c|c|c|c|c|c|c|}
\hline و قدمايران & خانقاه & قراديان & كائين آباد & كميز & فرجه & مباركآباد & قطارجيان & جورآباد & ثام روستا \\
\hline جنوب & غُشيى & غريى & غرب & غربى & شرق & غريى شمال & مركز & شرقي & موقعيت \\
\hline ireo & irep & irea & ime. & Iros & rex & ס מדוi & قبل از +•"rا & قبل از & محلوده زمانئي \\
\hline
\end{tabular}

منبع: شناسنامه آبادى هاى استان كردستان و سرشمارىهاي عمومى نفوس و مسكن، هوبها.
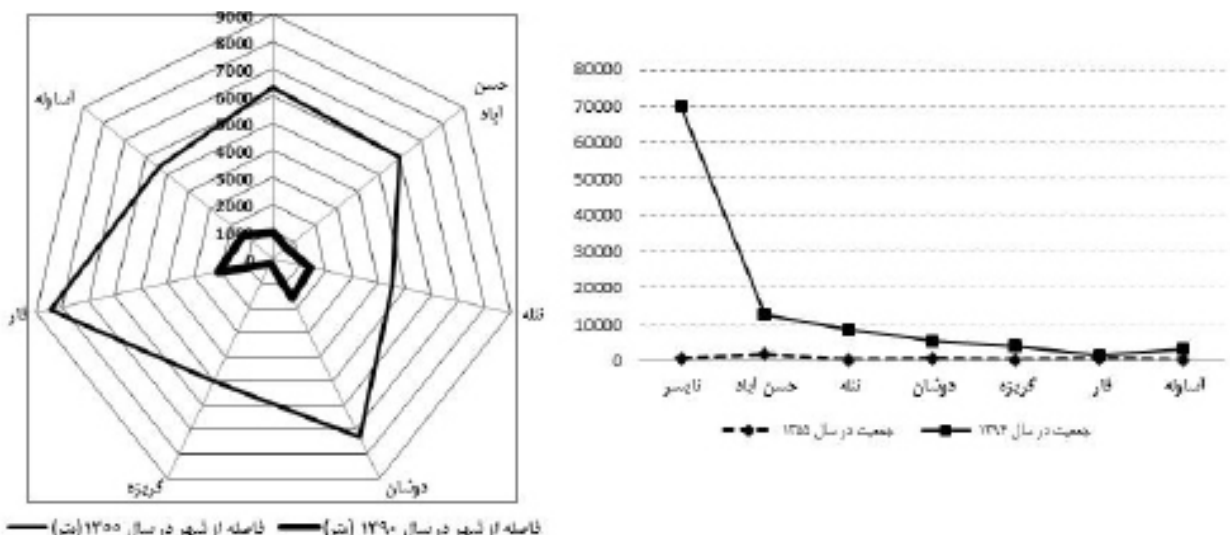

تصوير \& تغييرات جمعيتى و مسافتى روستاهاى درحال ييوستن به شهر ستندج. 


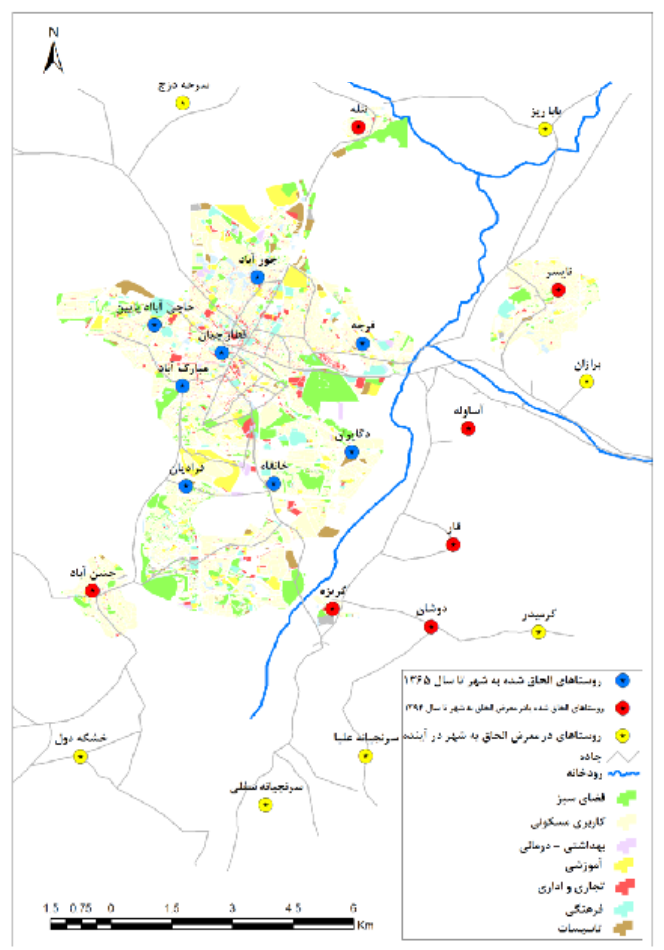

بدون احتساب مناطق منفصل شهرى نايسر، حسن آباد، نثله و

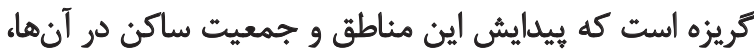

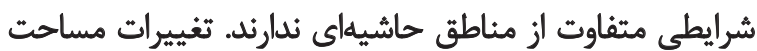

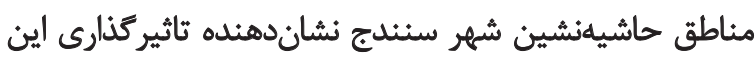

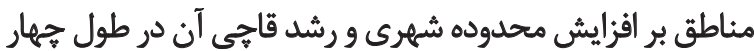
دها كذشته است (جدول شماره \&).

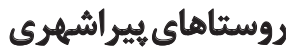

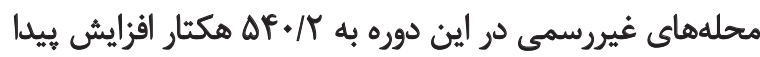

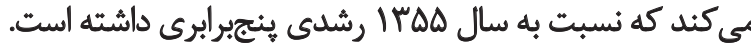

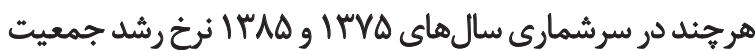

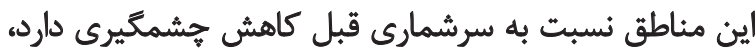

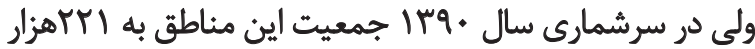

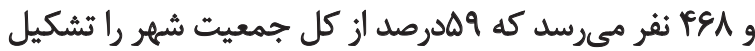

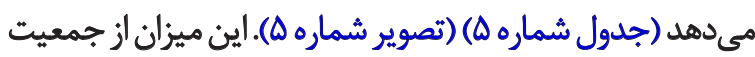

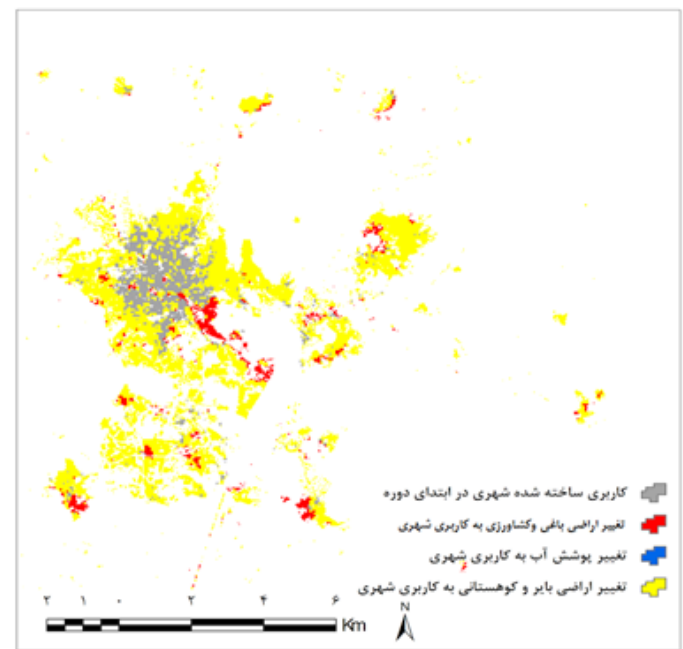


جدوله. مشخصات روستاهاى كروه سوم هيرامون شهر سنيدج.

\begin{tabular}{|c|c|c|c|c|c|c|}
\hline \multicolumn{3}{|c|}{ جمعيت (نفر) } & \multirow{2}{*}{ فاصله (كيلومتر) } & \multirow{2}{*}{ موقعيت جغرافيايى نسبت به شهر سنتدج } & \multirow{2}{*}{ 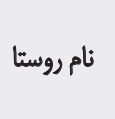 } & \\
\hline نَخ رشد & Irqp & IrAs & & & & \\
\hline$V / O$ & rAS. & Ifra & $r$ & شمال شرقي & باباريز & 1 \\
\hline$\Delta / 9$ & $p q$. & TqY & $1 / \Delta$ & 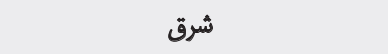 & 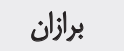 & r \\
\hline$r / A$ & $M+$ & $1 \Delta C$ & $r / \Delta$ & جنوب شرقى & كرميلر & $r$ \\
\hline$r / 9$ & NED & $8+9$ & r & جنوب شرقى & سرينجانه & r \\
\hline V/S & $1 . r_{*}$ & ATD & H/a & 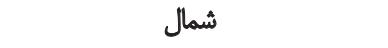 & سرخه دزج & $\Delta$ \\
\hline r/e & $\mathrm{rr}$. & $|A|$ & $r / \Delta$ & 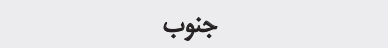 & خشكه دول & 8 \\
\hline
\end{tabular}

منبع: سرشمارى عمومى نفوس ومسكن، خائه بهداشت آبادىهاي مطالعهشده و نكارنده.

كه تعدادى از آنها با شهر سنيدج فاصله بسياركمى دارند و

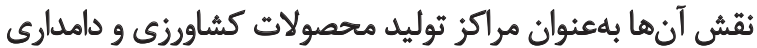

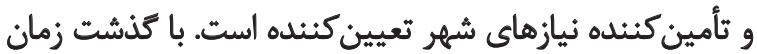

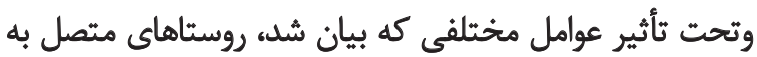

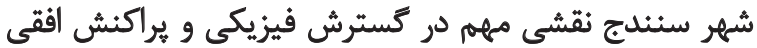
اين شهر داشيتهاند.

روستاهايى كه بلهور مستقيم در كسترش فيزيكى سنندج

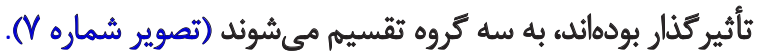

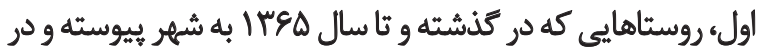

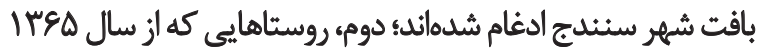

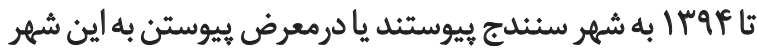

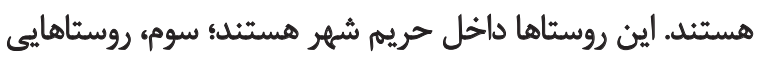

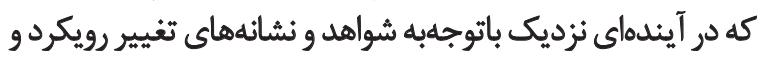

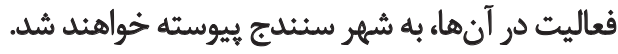

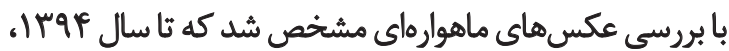

خزش شهرى از يهيامدهاى كسترش شتابان مادرشهرها بلويرثه

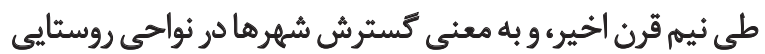

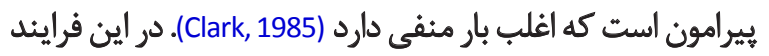

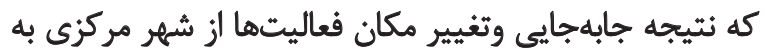

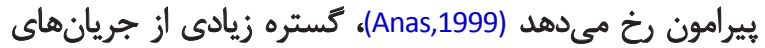

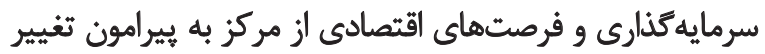

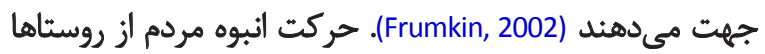

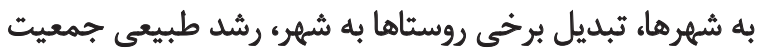

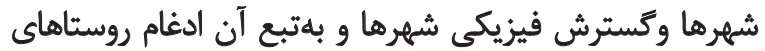

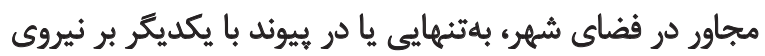

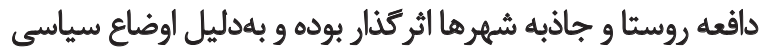
و اقتصادى و اجتماعى حاكم بر كشور به وجود آمدهاند. از جهار تهار

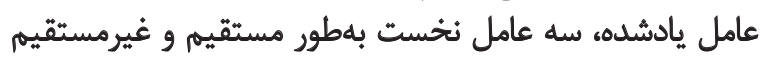

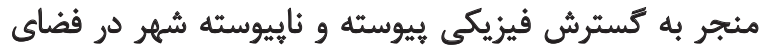
ييرامون مي شوند (Nazariyan, 2002). شهرستان سنئدج با مركزيت شهر سنئدج 19f روستا دارد

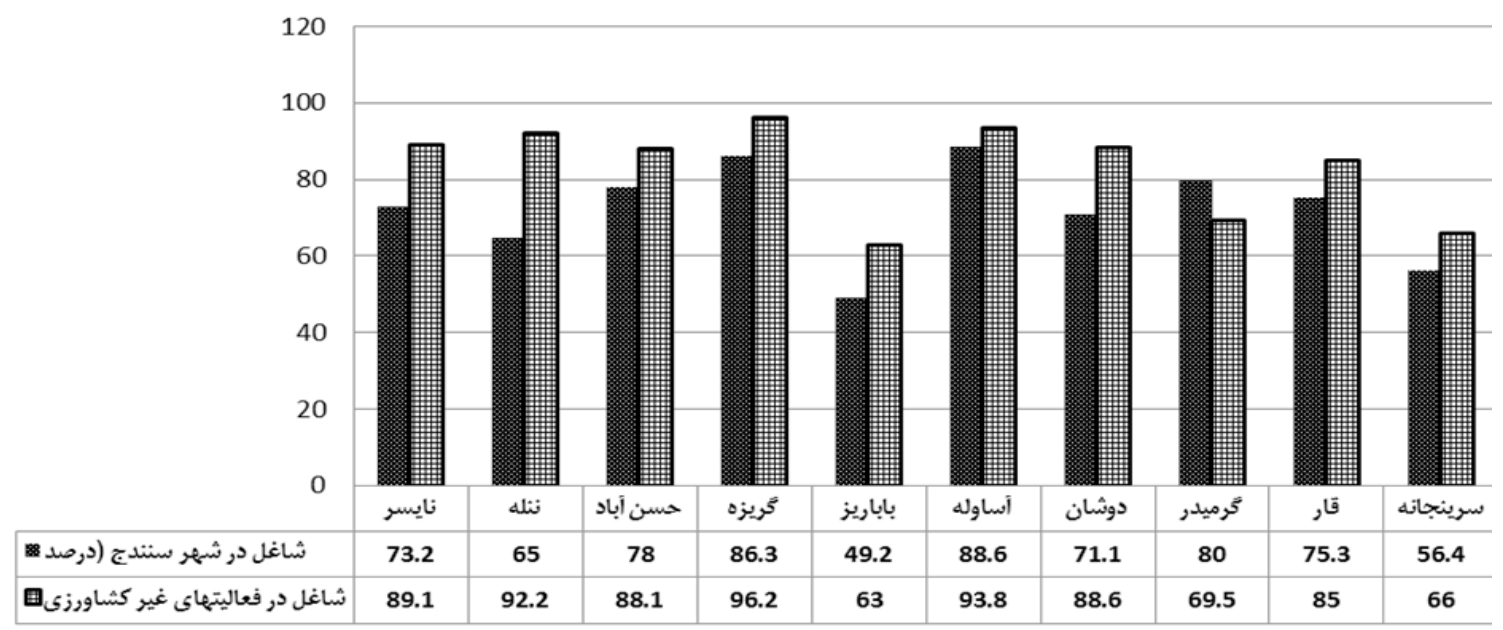




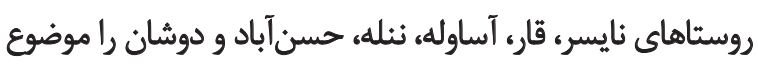

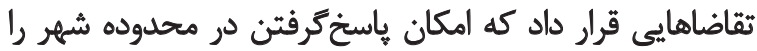
نداشتند. بين تقاضاى واقعى براى مسكن و قيمت زمين در داخل شهر

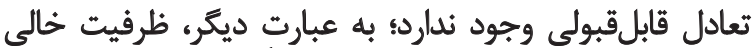

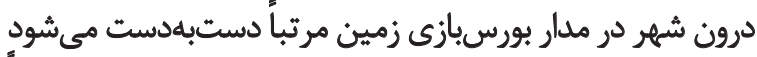

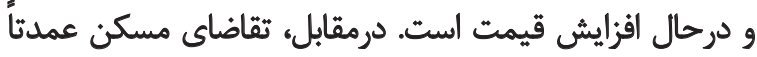

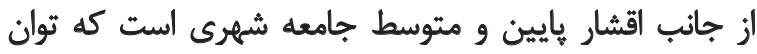

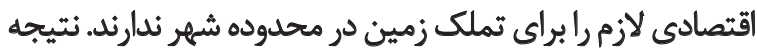

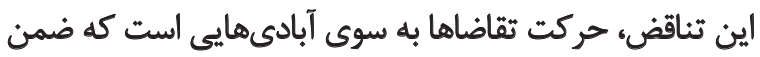

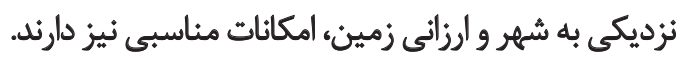

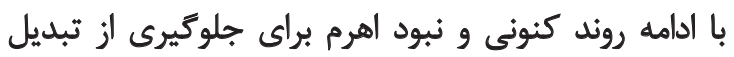

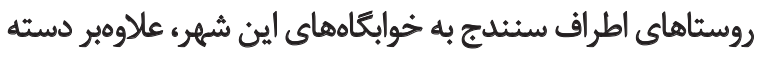

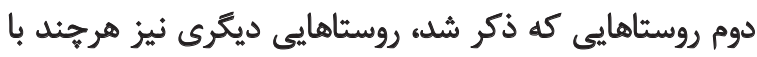

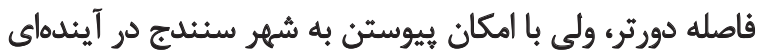

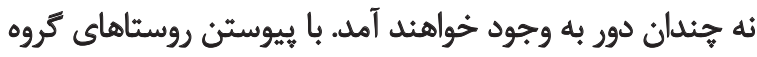

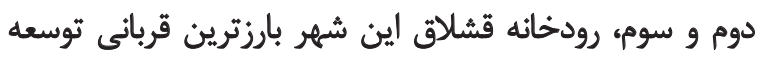

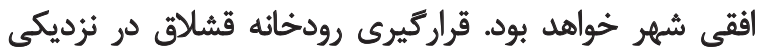

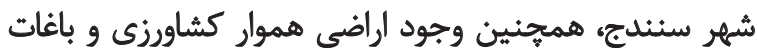

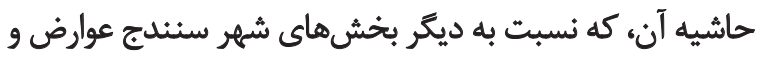

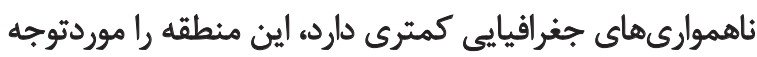
دلالان و زمين خواران قرار داده است.

رودخانه قشلاق در آينده باتوجهبه روند رشد و توسعه شهر،

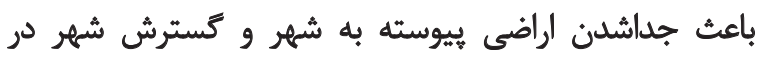

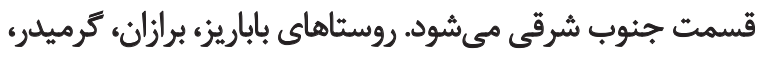

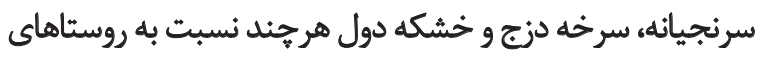

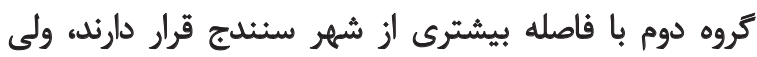

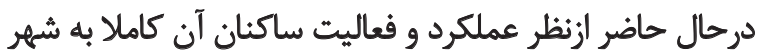

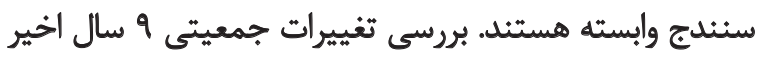

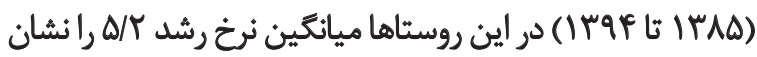

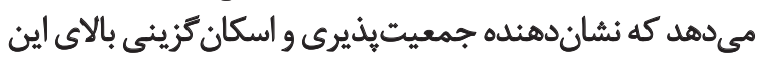

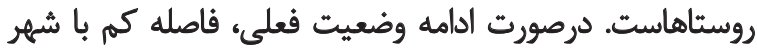

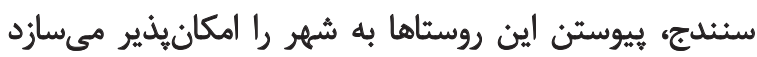

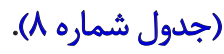

كيفيت و كتّيت دسترسى به شغل براى ساكنان در روستاهاى

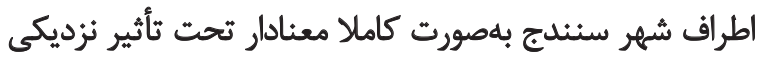

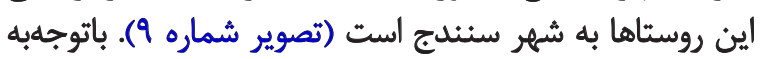

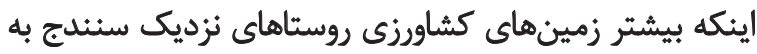

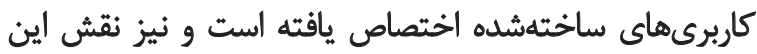

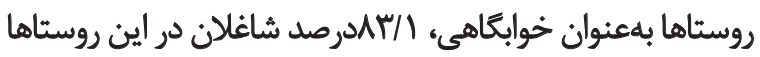

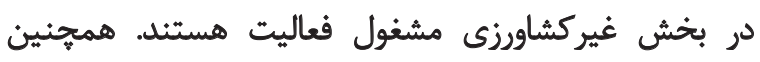

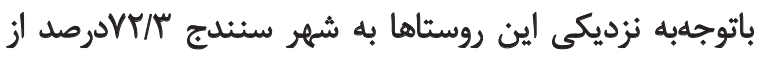

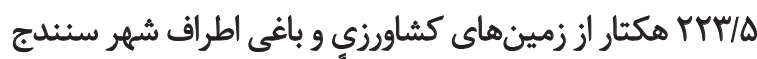

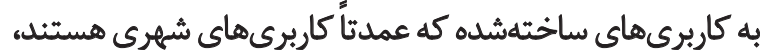

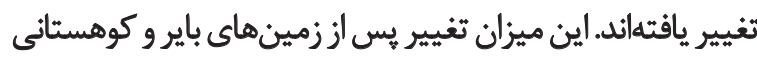

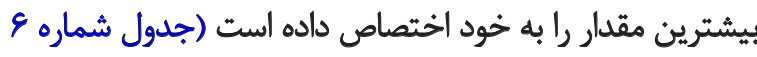

$$
\text { و تصوير شماره (). }
$$

شهر سنيدج بعداز انثقال از قلعه حسن آباد به يإى كوههاى

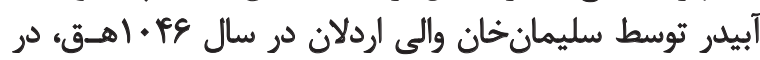

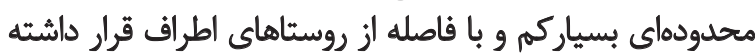

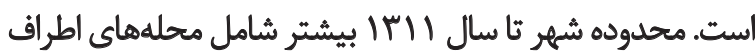

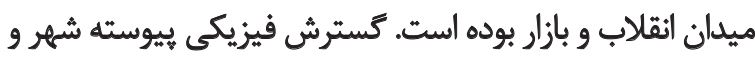

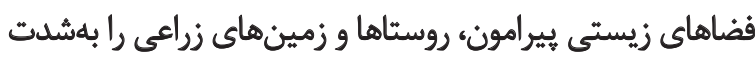

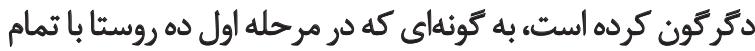

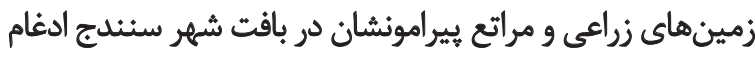

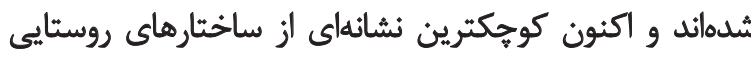

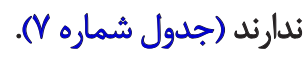

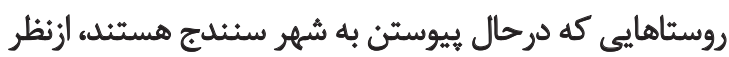

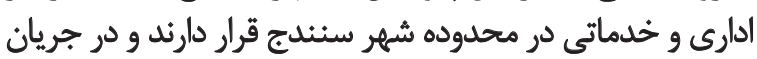

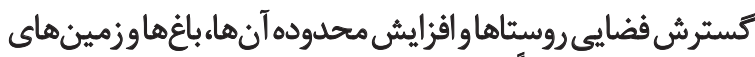

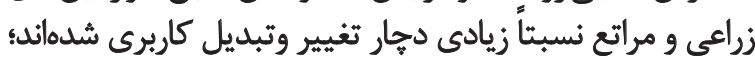

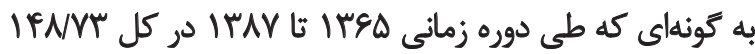

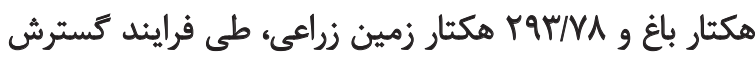

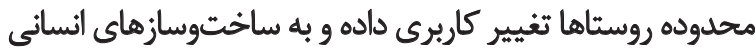
تبديل و در بافت روستاها ادغام شدهاند. (Ghadermarzi, 2009)

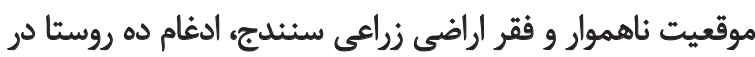

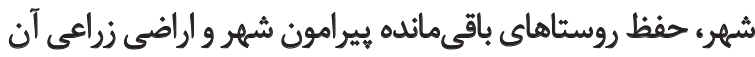
از جالشهاى مهمم مديران و برنامهريزان شهرى است.

وجود موانع توسعه كالبدى اطراف شهر از يكى سو و افزايش

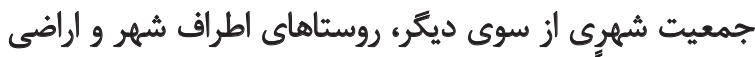

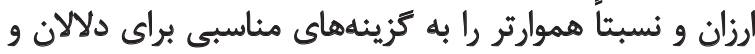

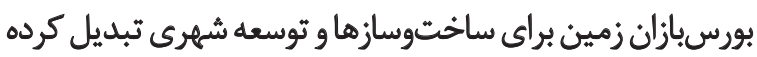

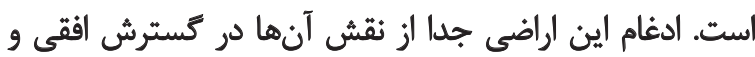

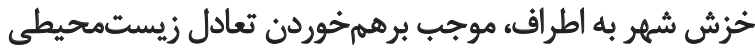

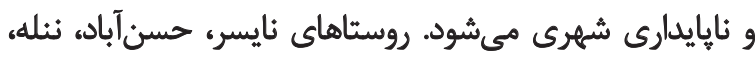

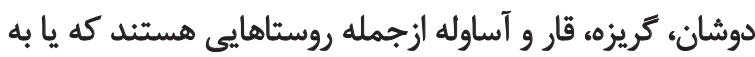

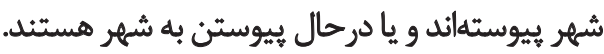

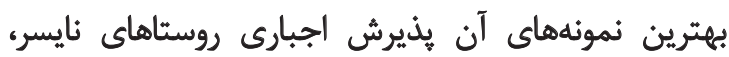

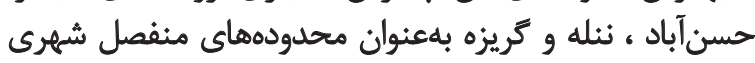

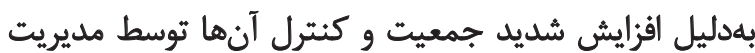

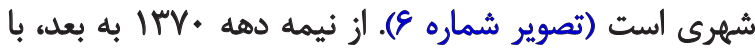

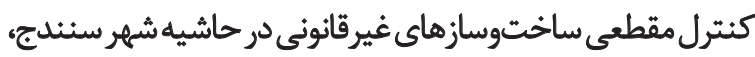

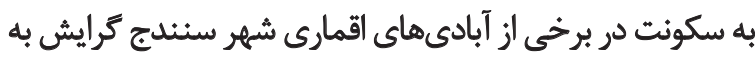

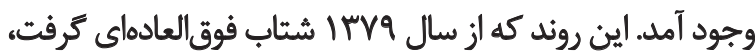


بسيارسريع جمعيت اين روستاها و فاصله كوتاه آنها نشانههايى از بيوستن آنها در آينده است.

$$
\text { تشيكر وقدرواني }
$$

اين مقاله از رساله دكتراى آقاى ناصح عبدى در دانشكاه بيام

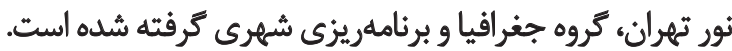

جمعيت شاغلان در شهر سنندج به فعاليت مىيردازند.

ه. بحث و نتيجهيَيرى

يافتههاى تحليلى و آمارها، كَسترش افقى ناموزون شهر سنيندج

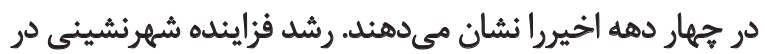

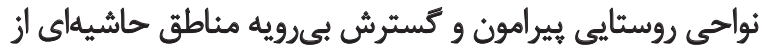

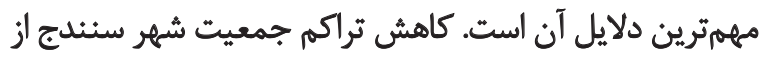

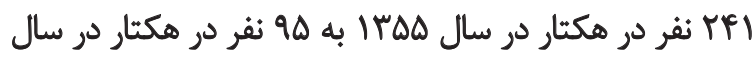

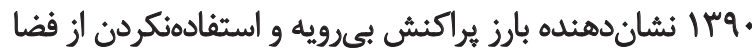

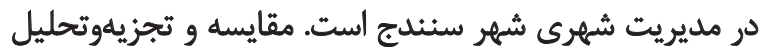

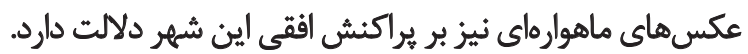

بررسى تصاوير ماهوارهاى نشان مىدهد كه محدوده شهر

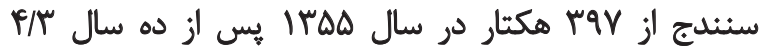

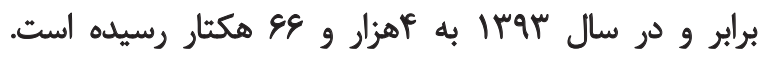

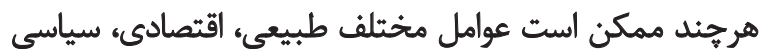

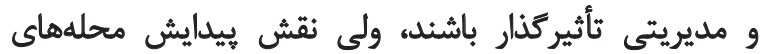

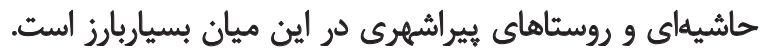

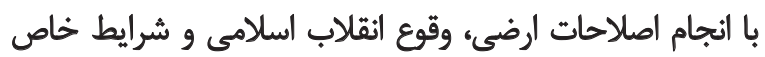

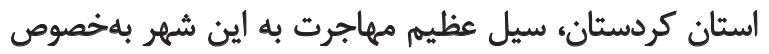

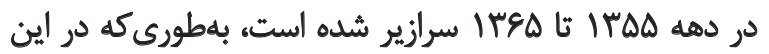

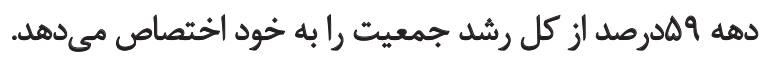

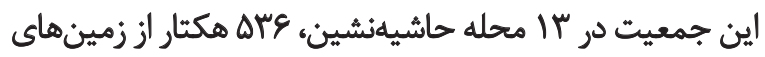

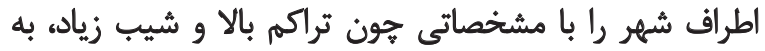

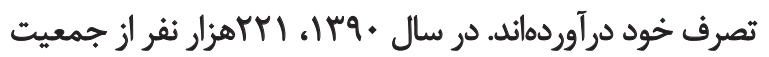

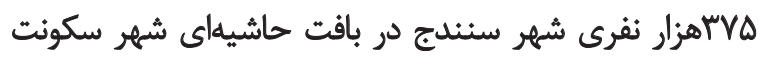
دارند كه اين ميزان در كل كشور بـسابقه است.

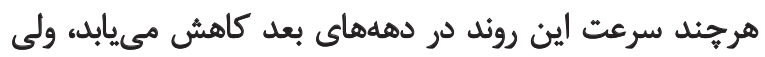

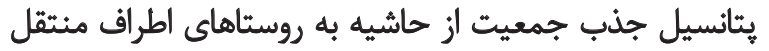

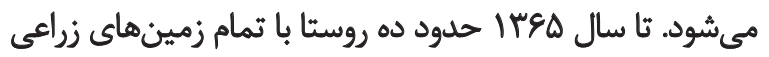

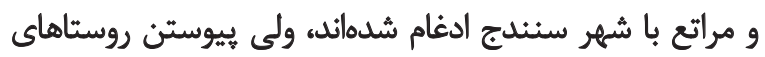

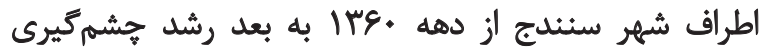

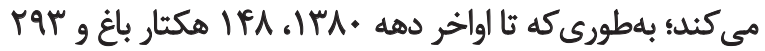

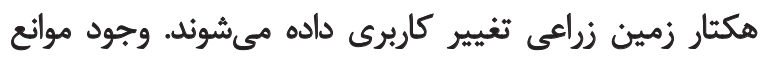

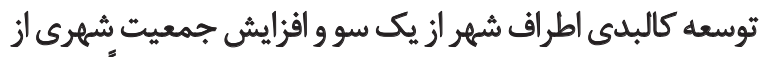

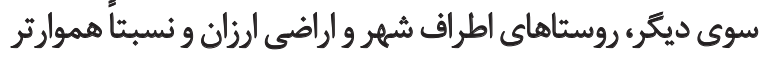

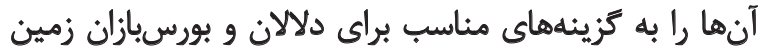

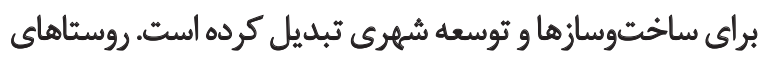

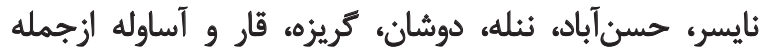

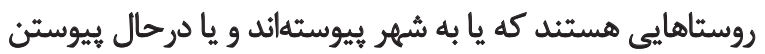

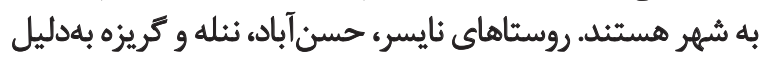

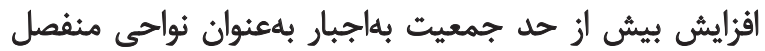

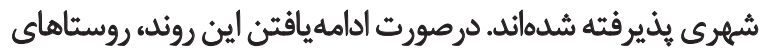
ديكرى نيز در انتظار يبيوستن به محدوده شهرى هستند. افزايش 


\section{References}

Abdi, N. (2005). [The impact of urban sprawl on the process of urban sustainable development (Persian)] (MA thesis). Tehran: University of Tehran.

Alonso, W. (1964). Location and land use. Massachusetts: Harvard University Press.

Anas, A. (1999). The cost and benefits of fragmented metropolitan governance, The new regionalist policies. Los Angeles, California: University of Southern California.

Anderson, W. P., Kanaroglou, P.S., \& Miller, E. J. (1996). Urban form, energy and the environment: A review of issues, evidence and policy. Urban Studies, 33(1), 7-35. doi: 10.1080/00420989650012095

Clark, A. N. (1985). Longman Dictionary of Geography: human and physical. United Kingdom: Longman Group.

Brueckner, J. K., \& Fansler, D. A. (1983). The economics of urban sprawl: Theory and evidence on the spatial size of cities. Review of Economics and Statistics, 65(3), 479-482. doi: 10.2307/1924193

Center of studies and researches of Iranian urban planning. (1989). In M. Rabati, \& A. Boshra (Eds.). Spatial Planning: Proceedings of Iranian cities. (pp. 33-49). Tehran: Ministry of Urban Development Publication.

Clark, A. N. (1985). Longman dictionary of geography: Human and physical. Harlow: Longman Group.

Eghbali, N., \& Rahimi, M. (2010). [Urban structure of Sanandaj in dominance of informal settlements (Persian)]. Human Geography Research Quarterly, 2(4), 57-72

Frumkin, H. (2002). Urban sprawl and public health. Public Health Reports, 117(3), 201-17. doi: 10.1093/phr/117.3.201

Gazerani, F. (2009). [Planning for balanced development of C.B.D of Snanadaj (Persian)] (MA thesis). Tehran: Shahid Beheshti University.

Jensen, J. R. (2005). Introductory digital image processing: A remote sensing perspective ( $3^{\text {rd }}$ ed.). New Jersey: Prentice-Hall.

Kamrava, M. A. (2009). [Contemporary urban planning of Iran (Persian)] ( $3^{\text {rd }}$ ed.). Tehran: University of Tehran.

Kendall, D. (2007). Sociology in our times: The essentials ( $8^{\text {th }}$ ed.). Boston: Cengage Learning.

Ladd, H. F. (1998). Effects of taxes on economic activity. In H. F Ladd (Ed.), Land Government Tax and Land Use Policies in the United States (pp. 115-131). Massachusetts: Edward Elgar Publication.

LaLiberte, L. J. (2009). Centripetal \& centrifugal forces (MA thesis). Florida: Atlantic University.

Lewis, P. G. (2001). Retail politics: Local sales taxes and the fiscalization of land use. Economic Development Quarterly, 15(1), 21-35. doi: $10.1177 / 089124240101500102$

Mahdavi, M. (2001). [Introduction to urban geography of Iran (Persian)] ( $3^{\text {rd }}$ ed.). Tehran: Samt Press.

Mardokh, M. (1972). [The history of Kurd and Kurdistan (Persian)].Tehran: Gharighi Prees.
Mashhadizadeh, N. (1994). [The analysis of the characteristics of the urban planning in Iran (Persian)]. ( $4^{\text {th }}$ ed.). Tehran: Science and Technology University Press.

Mieszkowski, P., \& Mills, E. S. (1993). The causes of metropolitan suburbanization. Journal of Economic Perspectives, 7(3), 135-47. doi: 10.1257/jep.7.3.135

Nazariyan, A. (2002). [The cities of future world (Persian)]. Paper presented at The international Conference on Cultural Approaches to Geography, Mashhad, Iran, 16-18 May 2002

Polese, M., \& Stren, R. (2000). The Social Sustainability of Cities: Diversity and the management of change. Toronto: University of Toronto Press.

Papoli Yazdi, M. H., \& Rajabi Sanjerdi, H. (2013). [Theories of city and periphery (Persian)]. Tehran: Samt Press.

Sanitary Center of Sanandaj Township 2001-2015. (2015). [Sanitary yearbook of Sanadaj (Persian)]. Sanadaj: Center of Health Publication.

Statistics Center of Iran. (2011). General census of population and housing, 1946-2011 (Persian)]. Tehran: Statistics Center Press.

Statistics center of Sanandaj Municipality. (2014). [Statistical yearbook (Persian)]. Tehran: Gohar publication.

The center of studies and researches of urban development. (1991) [Annual development statistics of urban development in Iran (Persian)]. Tehran: Center of Urban Planning.

The national organization of housing and land. (1996). [Statistics yearbook of land development in Tehran (Persian)]. Tehran: Ministry of housing.

Zanganeh Shahraki, S., Majidi Heravi, A., \& Kaviani, A. (2012). [A comprehensive explanation of factors contributed to horizontal urban sprawl of cities (Case study: Yazd City) (Persian)]. Applied Researches in Geography Sciences, 12(25), 173-93.

Zia Tavana, M. H., \& Ghadermarzi, H. (2011). [Land use changes of peri-urban villages in urban sprawl process (Case study: Naisar \& Hassanabad villages of Sanandaj) (Persian)]. Human Geography Research Quarterly, 42(68), 119-35. 
